\title{
Raúl Prebisch (1918-1930) ante el Poder-Saber
}

\author{
Carlos Mallorquin
}

Resumen. El ensayo intenta describir la formación y evolución del vocabulario teórico de Raúl Prebisch, así como las actividades y responsabilidades más importantes desde sus días estudiantiles hasta su confirmación como profesor universitario. Se destacan sus formas muy particulares de crítica y voluntad de poder y su innata cualidad de líder. El énfasis en las citas de Prebisch busca remarcar la personalidad del joven Prebisch, si es que alguna vez lo fue. La recientemente constituida Facultad de Ciencias Económicas de la Universidad Nacional de Buenos Aires presentaba una apertura política y pluralidad teórica muy singular. Prebisch es inmediatamente incorporado a varias de las tareas académicas de la facultad al mismo tiempo que busca empleo fuera de sus recintos. El relato termina unos días previos a su nombramiento como subsecretario de Hacienda y su incorporación como tecnócrata gubernamental.

Palabras clave: pensamiento latinoamericano, Prebisch, ciclos económicos, desarrollo, Buenos Aires.

Aвstract. This paper seeks to describe the development and evolution of Raúl Prebisch's theoretical thought, as well as his most important activities and responsibilities, from his early days as a student until his consolidation as a university professor. It highlights his particular way of critiquing, his willpower and his innate leadership qualities. Emphasis is put on quotes in order to underline Prebisch's personality when he was young, if he ever was. When it was first created, the Faculty of Economic Sciences at the University of Buenos Aires provided a political window of opportunity and a unique plurality of theoretical perspectives. Prebisch was immediately incorporated into some of the Faculty's diverse projects and simultaneously searched for employment off campus. The account ends a few days before he was named Minister of Economy, after which he became a government technocrat. Keywords: Latin American thought, Prebisch, economic cycles, development, Buenos Aires.

Carlos Mallorquin es profesor-investigador de la Unidad Académica de Estudios del Desarrollo de la Universidad Autónoma de Zacatecas. 
Antes, yo te buscaba en tus confines que lindan con la tarde y la llanura [...] En la memoria de Palermo estabas, en su mitología de un pasado [...] Te sentía en los patios del Sur y en la creciente sombra que desdibuja lentamente su larga recta, al declinar el día. Ahora estás en mí. Eres mi vaga suerte, esas cosas que la muerte apaga. (Borges, «Buenos Aires»,1964: 324)

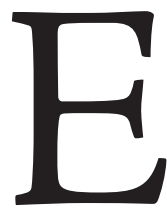
1 siguiente texto se ocupa de uno de los inefables ciclos que presenta la vida política e intelectual de Raúl Prebisch: parte con su arribo a Buenos Aires en 1918, para estudiar en la Facultad de Ciencias Económicas, y culmina a unos días de iniciar sus «años de gobierno», como diría Cortés (2001). Intenta dar cuenta del vocabulario conceptual de la formación teórica hasta 1930, cuando es nombrado subsecretario de Hacienda.

Dejando atrás Tucumán, no se puede negar la vorágine social y política que tuvo que haber sentido Prebisch al pisar Buenos Aires, ciudad que desde comienzos del siglo pasado ya tenía «dientes» (García Costa, 1997: 108), dadas las diversas victorias electorales de los socialistas. ${ }^{1}$ Sunkel ha dicho: «provino de la periferia de la periferia, para llegar enseguida a lo que podría en aquellos tiempos considerarse el centro de la periferia: una magnífica Buenos Aires que a comienzos del siglo pasado era una auténtica capital europea implantada en América del Sur» (Sunkel, 2008: 32).

/1/ Estrictamente hablando, Florencio Sánchez (García Costa, 1997: 108) emite la frase: «la Boca ya tiene dientes», cuando Alfredo Palacios fue electo en la Boca: distrito de Buenos Aires popular y entonces de extrema pobreza. 
Habiendo ingresado en la Facultad de Ciencias Económicas de la Universidad de Buenos Aires en 1918, la construcción y formación teórica inicial de Prebisch se da en un contexto académico en el cual la asistencia a clases no era inevitable. En aquel año, el movimiento de reforma universitaria en Córdoba liberó a los alumnos de la obligación de asistir a clases para certificar sus materias. Mientras ese trámite se materializaba en la facultad, Prebisch lo consagró con una huelga de «no asistencia» a las clases de, nada menos, Luis Roque Gondra (1932, 1933, 1934, 1937, 1943).

La interpretación de Prebisch sobre la reforma universitaria y sus expectativas van de paso con su desprecio a la planta académical: ${ }^{2}$

Este movimiento de reforma encierra un riquísimo contenido que podemos sintetizar en dos de sus manifestaciones principales: cambio en la orientación de los estudios universitarios y transformación de los métodos de enseñanza. [...] Y bien, ¿cuál es el terreno recorrido por nuestra facultad respecto a la reforma objetivamente considerada? Escasísimo. Indudablemente, algún progreso se hizo en los seminarios e institutos desde su creación; por otra parte, el actual decano [Eleodoro Lobos y sobre quien a pie de página agrega «Hay pues un buen germen...»] en repetidas ocasiones ha significado y acentuado su importancia, pero sus orientaciones se han visto desvirtuadas en la práctica. Y dos son los grandes obstáculos: uno, el más fuerte, de parte de los profesores, y el otro, menos intenso, de parte de los alumnos. Salvo contadas excepciones, los profesores que dirigen seminarios carecen de capacidad de investigación y por lo tanto no pueden desarrollar ésta en sus discípulos. Están imbuidos del viejo espíritu de la enseñanza. Leen, asimilan, sintetizan, repiten, y aun refutan ciertas teorías: trabajo —o investigación, si se quiere- puramente subjetivo. Más, trátase de estudiar objetivamente los hechos de nuestra vida económica

12/ También Prebisch, 1922b: 222; 218; 219 y 1921c: 65-66. 
- de nuestra economía nacional tan lamentablemente desconocida, pese al «nacionalismo» sui generis de muchos profesores [...] les faltó lo que ahora pedimos: buenos investigadores [...] Tan amplio es el horizonte de la reforma universitaria que en un momento llegó a concentrar aquellas nuevas tendencias, que este hecho aislado en el terreno de las manifestaciones concretas aparece de exigua importancia si se le compara con lo que aún queda por conseguir. En efecto, el movimiento de renovación iniciado en 1918, ha triunfado externamente al darnos representación en los gobiernos de las distintas facultades y al permitir que se nos tenga en cuenta en sus deliberaciones [...] (Prebisch, 1921c: 62-64).

En «Carácter y finalidad de los cursos de seminario», haciendo referencia al proceso de la Facultad de Ciencias Jurídicas y Sociales, insiste que:

Hemos hablado del seminario como un instituto de elaboración científica, diverso en su naturaleza y alcance del sistema de conferencias, sofoca el espíritu de investigación. La misma pasividad en que la mera exposición del profesor mantiene a su auditorio, no permite suministrar a los alumnos la preparación práctica que exige el ejercicio de la profesión [...] el seminario aspira a condensar en la práctica las nuevas corrientes metodológicas y el fermento que las anima. Tiende a penetrar gradualmente en el campo hoy monopolizado por las conferencias, sin pretender por ello negar no restar importancia a la función útil del profesor ordinario [...] el profesor abandona el aislamiento de su cátedra, para entrar en íntimo contacto con los alumnos. Juntos están frente a materiales inexplorados o cuyo conocimiento recién se elabora, y ofrecen, por lo tanto, extenso horizonte para la investigación. Con el método experimental penetran a través de su enredada urdimbre [...] Es en los seminarios donde a la vez que se reacciona contra el viejo método, al ejercitar al alumno en la investigación personal, el estudio de la realidad concreta es susceptible de tomar amplio vuelo (Prebisch, 1922d: 222; 218; 219). 
Debido a sus desplantes y a su lectura del medio ambiente de la facultad, es casi autodidacta, no obstante hubo profesores que tomaron en serio sus infatuaciones apoyándolo y asesorándolo en diversas tareas a las que fue crecientemente encomendado, a quienes Prebisch recuerda como importantes: Alejandro E. Bunge ${ }^{3}$ y Augusto Bunge. Del primero reconoce su proclividad y esfuerzo por la estadística; del segundo, su perspectiva de la cuestión social. Protegido, en parte, por cierto grupo de profesores y por el decano Eleodoro Lobos, Prebisch avanzó con muy buenos promedios en todas sus materias (Fernández López, 2008a). Nunca fue un erudito, pero leyó y estudió en la biblioteca de la facultad como ninguno. Privilegiado con el conocimiento del francés, italiano, inglés y, un poco, alemán, ${ }^{4}$ leía literatura y revistas de la época en dichos idiomas (Fernández López, 2001).

Roque Gondra, el mismo a quien Prebisch le organizó la huelga, puede ser considerado como uno de los impulsores más connotados de la escuela de Lausana en el mundo: el geómetra de la economía neoclásica más importante en América Latina. Con él llegó la matematización de la economía apoyada en una de las corrientes matemáticas hegemónicas de su tiempo sustentadas por Vito Volterra (Weintraub, 2002). Parte de esta labor fue realizada por Ugo Broggi (otro profesor de Prebisch), a quien tal vez escuchó decir que estaba intentando, mucho antes que Debreu, probar la existencia del «equilibrio general». De Ludwell Moore leyó que había que dudar que la ciencia económica podía «modelarse en las ciencias matemáticas más simples, las ciencias físicas», una especie de «cálculo de placer y dolor», una «mecánica de la utilidad», una «mecánica social», una physique sociale (Moore, 1914: 85). Pero Moore insistía que para llegar a las «leyes» se requerían aproximaciones sucesivas: el «método que progresa de los datos a la generalización por medio de una sínte-

\footnotetext{
13/ «Me llevó, siendo yo estudiante, a la Dirección de Estadística como supernumerario de su secretaría» (Prebisch, 2006). Para Bunge, ver Caravaca (2012), Molteni (2003) e Imaz (1974).

/4/ Tuve una conversación con Adela de Mol de Prebisch en 1995.
} 
sis progresiva —el método estadístico» (Moore, 1914: 86). ${ }^{5}$ De la estadística, Prebisch nos recuerda, a nota de pie de página, la «formula general de correlación $=\mathrm{r} \sum(\mathrm{xy}) / \mathrm{n} \sqrt{\mathrm{x}} \sqrt{\mathrm{y}}[\ldots]$.. Su deducción puede verse muy bien expuesta en G. U. Yule, Introductory to the Theory of Statistics' (sic)» (Prebisch, 1920i: 39).

Tempranamente, se le solicitan traducciones, como la Wagner del francés (Les Fondements de l'Economie Politique), Barone (Principii di Economia Politica) del italiano y, por cuenta propia, realiza la de Williams (Argentine International Trade Under Inconvertible Paper Money, 1880-1900). En un medio ambiente académico sin hegemonías teóricas de ningún tipo, en el sentido contemporáneo, Prebisch leyó de todo: de Marx a Turati en la tradición socialista, así como los cooperativistas, el «socialismo de Guildas» y asociacionistas anglosajones como Cole y a Hobson leído por Lenin. Conoció tanto al Pareto del «Manual» como al «otro Pareto», el de la «sociología». ${ }^{6}$

Pronto transita de «ayudante» a «jefe de seminario» $y$ «jefe de trabajos prácticos» de varias de las materias y seminarios. Asumió precipitadamente un protagonismo para escribir, ${ }^{7}$ traducir $^{8}$ y publicar notas y artículos en la Revista de Ciencias Económicas de la facultad (inaugurada en 1913). Unos años en sus estudios, para mediados de 1921, Prebisch (1921c) ya formaba parte de la codirección de la revista conjuntamente con la facultad. En 1920 es la primera ocasión en que Prebisch (1920e; 1920g) publica en la revista dirigida por Alejandro E. Bunge, en la Revista de Economía Argentina (inaugurada en 1918). ${ }^{9}$ Entre sus primeros años de escritura y publicación, se reflejan estudios en torno a la cuestión del «standard de vida» y los números indicadores

\footnotetext{
15/ Tal vez Prebisch se percató, como lo hizo Morgan (1990), de la distancia entre la prédica de Ludwell Moore y sus propuestas.

16/ Prebisch, 1923c.

17/ Prebisch, 1919a; 1919b; 1919c; 1919d; 1919e; 1919f; 1919g. Manuel Fernández López menciona otros textos realizados durante 1919 (Fernández López ,1991) que parecen haberse extraviado.

/8/ Prebisch, 1919g; 1921f.

${ }^{19 /}$ De hecho el texto de Prebisch (1920g) se publicará nuevamente en la revista dirigida por Alejandro E. Bunge.
} 
y su construcción, ${ }^{10}$ así como diagnósticos sobre la situación financiera internacional ${ }^{11}$ y la estabilidad «monetaria». ${ }^{12}$ Con tan sólo 19 años, Prebisch, aparentemente sin medir ningún tipo de riesgo, publica uno de sus primeros escritos, que por su tono y repercusiones dan primicia de su personalidad y voluntad de poder. «¿Salarios a oro?» (Prebisch, 1920a) se publica en la revista La Hora — «que estaba en la extrema izquierda del Partido Socialista» (Prebisch, 2006) - , con el apoyo de Augusto Bunge, su profesor en la facultad y director de la revista mencionada. La publicación del trabajo a un joven no «afiliado» ${ }^{13}$ al partido será objeto de crítica y discusión entre Bunge y el líder supremo del Partido Socialista argentino, Juan B. Justo (primer traductor de El Capital de Marx del alemán al español y publicado en Madrid en 1898). ${ }^{14}$

De hecho, el artículo cuestionaba la postura del partido de utilizar el oro como base del sustento y medición para defender los salarios y su poder adquisitivo. Prebisch contradice la tesis señalando que el mineral también sufría un proceso de desvalorización. Hipótesis aparentemente descabellada para la época del dominio del patrón oro como sustento de las reservas y base de los cambios internacionales: fue en parte un verdadero chispazo de intuición juvenil, aspecto de una reflexión que se presentará, una y otra vez, en sus críticas a Justo y al discurso económico.

Debe señalarse que el circuito social y político no estaba radicalizado: por ejemplo, en cuanto al tema de la reforma agraria, Eliodoro Lobos, catedrático y primer decano de la Facultad de Economía, en el periodo de la reforma universitaria, escribió sin resquemor alguno que «las tendencias extremas y conservadoras de la política argentina coinciden, en estos días, en la misma as-

\footnotetext{
/10/ Prebisch, 1919a; 1919b; 1920a; 1920b; 1920e; 1920i; 1920j.

/11/ Prebisch, 1919g; 1920f; 1920h; 1921b; 1921d; 1922c; 1923a.

/12/ Prebisch, 1921e; 1921g; 1921a.

${ }^{113 /}$ En una de las entrevistas, Prebisch indica que Justo dijo «joven peligroso». A raíz del episodio Prebisch decidió no aplicar para su ingreso al Partido Socialista Argentino (Prebisch, 2006).

/14/ Braun, 2000: 43.
} 
piración y, sin duda, con igual sinceridad, cuando declaran en actos recientes y públicos que la legislación nacional debe afrontar sin retardo la cuestión agraria» (Lobos, 1925: xxxII-XxxiII).

Las circunstancias que rodean la publicación antes mencionada y la personalidad del autor explican mucho el tono y el vocabulario beligerante reflejado en sus primeros años en la facultad. La publicación también demuestra los inicios de la reflexión sobre los números indicadores, proyecto crucial en la vida intelectual de Alejandro E. Bunge (Molteni, 2003; Imaz de, 1974), y que se convierte en uno de los primeros intereses académicos y políticos de Prebisch.

En «La cuestión social», Prebisch (1920b) planteaba que la evolución social era inevitable y que los regímenes sociales debían adaptarse a los cambios sociales, mutaciones que debían ser encausadas y cuya tarea recaía en «los gobiernos». Las «bases materiales» («económicas») son el sustento del movimiento histórico, dice Prebisch; sin embargo, no acepta plenamente la idea de que la historia se rige por la «lucha de clases» de Marx y Engels, y adopta mejor la expresión de Turati sobre «cooperación de clases». Citando la historia del socialismo presentada por Anton Menger (1899), piensa que la evolución social culminaría en el establecimiento del «derecho al producto íntegro del trabajo» (Prebisch, 1920b: 12). ${ }^{15}$

Por doble partida, sin embargo, es Irving Fisher quien predomina en el horizonte y el vocabulario de Prebisch, por un lado, por sus modelos de cons-

115/ «The right to the whole produce of labour is simply incompatible with our present society, which in greater part of Europe recognizes private property in land and capital. Under a legal system which unites common property with separate usance, the right to the whole produce of labour is the natural principle of distribution. In a communistic organization of society, which combines common property and common usance, the realization of this right seems at first sight not impossible; but a nearer consideration of the circumstances reveals so many impracticable difficulties that in such a community the natural basis of the distribution of wealth must be sought in the right to subsistence. [...] But is the tendency of our social development towards the realization of the right to the whole produce of labour, or of the right to subsistence? Many signs would seem to point to the latter» (Menger, 1899: 174, 176). 
trucción de los números indicadores y, por otro, por la «teoría cuantitativa de la moneda» que se «hace más clara», «expuesta en una sencilla fórmula matemática», «la ecuación del cambio» «MV $=\sum \mathrm{PQ} »$, «donde se ve que permaneciendo $\mathrm{v}$ y $\mathrm{Q}$ invariables y aumentando o disminuyendo $\mathrm{M}$, o sea la cantidad de moneda en circulación, los precios, o el nivel general de precios, aumentarán o disminuirán proporcionalmente» (Prebisch, 1921a: 180-181). El acercamiento de Prebisch a Fisher se da a través de la comunicación epistolar y proyectos similares entre Fisher y Bunge sobre el «coeficiente de corrección de la moneda»y los «números indicadores» que se señalan en «S Salarios a oro?» (1920a). Es parte de su aproximación a la problemática del «costo de la vida» y la base para defender la paridad de los salarios. La problemática y la reseña de «Stabilizing the Dollar» de Irving Fisher (Prebisch, 1920g) hace posible una nueva disquisición en torno a Justo. Un año más tarde, en el contexto de la discusión en la Cámara de Diputados sobre la conveniencia o no de abrir la caja de conversión, ${ }^{16}$ Justo aprovecha la ocasión para publicar la tercera edición de Estudios sobre la Moneda en 1921. Prebisch reseña el libro y no pierde la ocasión para señalar la diáfana capacidad de exposición de Justo y, de paso, las críticas («errores»).

Prebisch niega el supuesto de las «emisiones excesivas» que Justo menciona para explicar la situación monetaria de la década de 1880; la cuestiona diciendo que «brillaron por su ausencia»: la «pretenciosa Ley Monetaria del 81 » implicó que los billetes envilecidos sean cambiados por «billetes metálicos» a razón de 25 pesos antiguos por uno del nuevo en la Caja de Conversión, o sea, anclándolos a un valor-base oro. Por tanto, el colapso y la crisis de 1885 , y la subsecuente «inconversión y el agio o premio oro» «se deben únicamente a un balance de pagos adversos, no interviniendo en absoluto en estos fenómenos la cantidad de signos monetarios» (Prebisch, 1921e: 59).

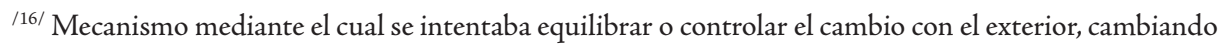
a cierta tasa oro por pesos cuando estaba «abierta»; sobre la misma diremos algo más adelante. 
Como podemos observar, con estas tempranas y controversiales interpretaciones Prebisch culmina convirtiéndose en un historiador de la cuestión monetaria y financiera argentina e internacional. De hecho, unos meses más tarde tuvo que aceptar como correcta la tesis de Justo. Ahora su lectura y reseña del libro queda supeditada a la lectura de Williams ${ }^{17}$ sobre las cuentas externas argentinas entre 1880 y 1900 , autor que obviamente lo tenía seducido $^{18}$ (Prebisch, 1921h: 139; 141):

En cuanto a la circulación de billetes, si bien es cierto que se redujo de cerca 900 millones de pesos moneda corriente redundantes e inconvertibles, a que ascendía al comenzar la década, a un valor relativamente insignificante de billetes convertibles, en cumplimiento de la Ley Monetaria y de los decretos posteriores que obligaban a los bancos a remplazar billetes por notas metálicas pagaderas a la vista y al portador, ello fue debido a la sencilla prestidigitación consistente en remplazar veinticinco billetes antiguos por uno nuevo, amparada por los balances de pagos favorables. Y este «truc» es lo que seguramente ha inducido a Williams a sostener que en el periodo considerado no bubo emisiones de billetes, y que lejos de ello, la masa inconvertible fue grandemente reducida al cambiarse por notas convertibles: error que repetimos nosotros al ocuparnos hace algunos meses del opúsculo del doctor Justo sobre la moneda. La afirmación es doblemente falsa, desde que, en primer lugar, los billetes inconvertibles sólo fueron remplazados en parte por notas metálicas, aunque su valor total se redujese al computarse cada veinticinco de sus unidades, por un peso moneda nacional. Es así que en un informe

${ }^{117 /}$ Prebisch sintetiza y traduce el libro de Williams, Argentine International Trade Under Inconvertible Paper Money, 1880-1900 (Cambridge, Harvard University Press, 1920), en 1921 y se publica en cinco números la Revista de Ciencias Económicas (ver Sembert, 2010).

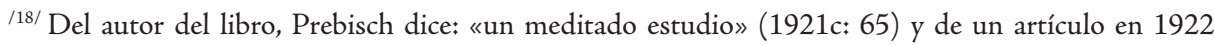
utiliza un inusitado vocablo: «brillante artículo» (Prebisch, 1922e: 228). 
presentado al gobierno en enero de 1885 por lo bancos, aún se lee «circulación a pesos fuertes», a «moneda corriente», y a «bolivianos». En segundo lugar, hubo emisiones crecidas en este periodo si bien es cierto que fueron convertibles [...] Pero agotados los medios para hacer frente a las exigencias del mercado de cambios [...] el gobierno autoriza a los bancos suspender sus pagos en especie en enero de 1885. Para producir la inconversión actuaron [...] factores análogos a los que determinaron el colapso del 76. El desequilibrio en el balance de pagos, en primer lugar, determinó la baja de cambios y la necesidad de exportar metálico [y] a deplecionar las reservas de los bancos, exiguas en relación al monto de los billetes emitidos [...] en los dos últimos años. En segundo lugar, estas emisiones desproporcionadas de billetes causaron una mayor elevación de los precios, y estimul[aron] [...] las importaciones que llegaron a su máximo en 1884, y que junto a la disminución del saldo de préstamos fueron causantes del desequilibrio en el balance. Pues es a través de este mecanismo del comercio internacional que las emisiones excesivas de papel presionan sobre las existencias de oro, determinando su exportación. Es así que el déficit [...] en el balance de préstamos [...], y las escasas reservas de los bancos oficiales [...], fueron los determinantes de la suspensión de los pagos metálicos. De este modo completamos la explicación que de este fenómeno presenta Williams, al ponderar las influencias de las emisiones excesivas cuya existencia él desconoce.

Sustentándose en dicho texto, Prebisch (1921h: 139; 141) intenta, en parte, recuperar en el diagnóstico la pertinencia de la noción de las «emisiones» excesivas mencionadas por Justo que antes había negado. Entre crítica y aclaraciones, Prebisch presenta su postura política de la reseña a Justo:

Pero el hecho de atribuir al balance de pagos un papel a lo menos tan importante como el de las emisiones excesivas en unos casos, y el de presentarle como única causa del agio en otros, no significa la contemplación 
menos severa de la política administrativa y monetaria extravagante y con frecuencia deshonesta de los gobiernos. Si divergimos con el doctor Justo en el modo de analizar ciertos fenómenos, nos solidarizamos con él en la manera de juzgar los acontecimientos en esta época de desenfrenada especulación [...] La parte más nueva de esta edición de los Estudios sobre la moneda la constituyen unas breves anotaciones sobre la depreciación actual del papel moneda argentino debida primero a que no es convertible en la Caja de Conversión ni circula en el país, y segundo, a la desvalorización arbitraria del oro que está en el país, por la prohibición de exportarlo. Concluye el autor pidiendo la apertura de la caja en lo que estamos de acuerdo (Prebisch, 1921e: 60).

Sus tres principales escritos en 1921, «La ortopedia Bancaria del profesor Piñero» (Prebisch, 1921g), «Anotaciones sobre nuestro medio circulante» $(1921 \mathrm{~h})^{19} \mathrm{y}$ «Planes para estabilizar la moneda» (Prebisch, 1921a), sellan su pasión por la temática monetaria y financiera. Pero esta reflexión está determinada por un profundo desagrado que surge de la lectura del libro del «doctor Norberto Piñero», La Moneda, el crédito y los bancos en la Argentina (1921), «libro» que...

[...] orientado casi siempre hacia la interpretación de los textos y la búsqueda de las intenciones del legislador, y no la indagación de la realidad. No creemos equivocarnos al decir que el nuevo libro no llena el vacío anotado. Su autor, ortodoxo de la escuela criolla de economía, no rompe nuestro clásico molde. Por otra parte nada fundamental hay en este libro, que no se pudiera encontrar en anteriores, sin que el presente llene lagunas y deficiencias o contribuya a la dilucidación de fenómenos en que aquellos no tuvieron éxito (Prebisch, 1921h: 94).

/19/ Este texto contiene cuatro partes, se publican como artículos; dos se publicaron en 1921 y las otras dos en 1922. En Raúl Prebisch, Obras 1919-1948, tomo I, Fundación Raúl Prebisch, Buenos Aires, 1991. 
Podríamos reiterar estos señalamientos, pero es suficiente decir que Norberto Piñero ${ }^{20}$ prácticamente desaparece de la narrativa monetaria y financiera en un escrito que abarca 85 páginas. Se convirtió en una excusa para describir y reflexionar sobre los desórdenes financieros del viejo régimen que culmina con la revolución de 1891.

A lo largo del texto, Prebisch realizará una historia bancaria y monetaria de varios siglos, pero concentrándose en el siglo xix y comienzos del siglo xx.

En la historia monetaria argentina, a pesar de su confusa apariencia, nótase una serie de periodos de ilimitada confianza y prosperidad, de expansión en las transacciones, de especulación inmobiliaria y fantasía financiera; seguidos de colapsos más o menos intensos, precipitados en pánicos que originen la liquidación forzada de las operaciones, el relajamiento de la confianza, la postración y el estancamiento de los negocios. Sin duda, cada uno de estos ciclos no se presentan exactamente en las mismas condiciones, ni con idéntico carácter; pero, considerados en conjunto, es posible encontrar en ellos hechos fundamentales que se repiten, cuyo análisis permite formular síntesis acerca de su evolución. Y no es que al hacer esta afirmación, al parecer apriorística, estemos influenciados por la descripción del proceso clásico de la crisis formulado por algunos economistas. Lejos de ello, buscaremos demostrar que en nuestras crisis, aparte de las diferencias de menor cuantía, interviene un factor fundamental, ausente en las crisis europeas y peculiar al grado de formación histórica del país. Para ello, nos hemos valido de los datos acumulados en la obra del doctor Piñero y en otros trabajos que citaremos en texto. Asimismo, la lectura de la obra del profesor italiano Lorini

/20/ No confundir el texto referido con la crítica que Prebisch realiza a la propuesta de proyecto bancario de Sergio Piñero: «La ortopedia Bancaria del profesor Piñero», (Prebisch,1921g); «exprofesor» suyo sobre sus proyectos de un «Gran Banco de Estado». 
sobre la cuestión monetaria argentina a fines del siglo pasado — respecto a las críticas acerbas en gran parte infundadas, de que fue objeto, nos ocuparemos en otra ocasión - y la de John H. Williams, nos ha descubierto un horizonte nuevo sobre nuestros problemas monetarios e indicado el método a seguir en sus estudios (Prebisch, 1921h: 95).

Da cuenta de la fundación de los bancos nacionales y el de la Provincia, la «oficina de Cambios y la Caja de Conversión». Derrocha tinta destacando los innumerables textos teóricos de economía e históricos de la cuestión monetaria de Argentina. El movimiento de independncia copió proyectos bancarios en boga de instituciones que no podían perdurar, el «error consistía» en que correspondían a un «grado superior de desarrollo económico» (Prebisch, 1921h: 107) que el argentino. Pero obviamente, de la narrativa no se podía excluir a Manuel Moreno: «entre la vorágine de falsos conceptos, destácase la teoría sana» (ibid). Proyecto aparecido de forma anónima en 1825, decía: «Los bancos por sí solos, no crean riquezas, si bien, cuando éstas preexisten, dilatan la esfera del capital, y los recursos que resultan de su más pronta y ventajosa circulación [...] El país que no se encuentre circunstancias tan favorables, no necesita bancos». Respecto a lo último, entendía que «con exclusión del solo pueblo de Buenos Aires (esfera a que se limitaban las operaciones bancarias) las provincias del Río de la Plata no se hallaban todavía en aptitud de formarlos y sostenerlos» (Prebisch, 1921h: 107).

De hecho, intentando describir el caos de la circulación monetaria («anárquica»), de las provincias que «respondían a condiciones de hecho, que simples leyes monetarias no podrían alterar» (ibid: 148), vemos la aparición de los vocablos centro-periferia. Dado que el sistema colonial español desvirtuó con prohibiciones ciertas vías del comercio, tanto mercaderías como personas expandieron su radio de acción desde el centro hacia la periferia, en contraste con lo ocurrido en Estados Unidos (ibid: 149).

Prebisch quiere resaltar las «fuerzas» que generan los mecanismos mediante los cuales se impulsan las emisiones monetarias y, por tanto, las co- 
rrientes inflacionarias, el desproporcionado crédito, el «encaje» desvirtuado y las fantasías de prosperidad o capitales «ficticios». En contraste, el...

[...] doctor Piñero sostiene que la Ley de 1881 «tiene un fundamento científico» pues se basa en el sistema métrico decimal (sic) y llevando al extremo su superstición legalista, continúa la apología al decir que «produjo efectos importantes y permanentes» y que «ien su virtud se restableció la circulación metálica y desapareció la anarquía monetaria!» Pero el hecho fundamental sobre las importaciones de metálico y los préstamos extranjeros, es el haber actuado como causas objetivas de un nuevo periodo ascendente, análogo al de la crisis anterior. La propiedad inmobiliaria, cuyos valores se habían deprimido a fines de aquélla, comenzaba de nuevo a inflar sus precios. Los precios volvíanse más activos al calor de la facilidad del crédito y a la vez reaccionaban sobre éste, en el sentido de su mayor expansión; tal abundancia de crédito se basaba en el aumento real de los bancos oficiales, que, como se recordará, estaba constituido por oro prestado, y el crecimiento de los depósitos de la clientela, proveniente de la mayor cantidad de circulante monetario. Y el crédito no sólo se concedía al comercio y la industria: la política criolla no tardaría en manosear sus resortes. [Remata citando a Quesada, Historia de los Bancos Modernos (1901)]: «Los préstamos llamados habilitadores ya no sirvieron para facilitar recursos a toda clase de negocios, sino que se concretaron a los políticos, a los que traían adherentes a candidaturas en embrión y a dar fondos a los comités por medio del descuento de letras a apersonas imaginarias para terminar en los grandes descuentos que servían a las especulaciones de los allegados a los que dirigían los destinos económicos de la desgraciada provincia de Buenos Aires». Como se ve, por segunda vez que el criollo habilitador a largo plazo, servía menos a los intereses rurales, como sostiene sus panegiristas que a los enjuagues bancarios (Prebisch, 1921h: 138) [...] Al mismo tiempo, los nuevos préstamos externos disminuyeron en este año mientras se acre- 
cientan los servicios contratados en los otros años. Es así que el balance de préstamos, favorables en 7 millones en 1883, tórnase desfavorable en el año siguiente, en la suma de 13 millones de pesos moneda nacional (papel u oro), trayendo consigo la baja de los cambios y la necesidad de exportar metálico (Prebisch, 1921h: 140)

Igualmente, Prebisch insiste que otra causa no...

[...] menos importante del aumento de la deuda pública fueron los déficit en los presupuestos, que en esta época de imprevisión, excitación y corrupción administrativa alcanzaron a sumas inusitadas. [...] De ahí que el déficit haya sido una de las causas determinantes del colapso, contrae un compromiso externo (si es que aquélla no estaba ya radicada fuera del país), pues el mercado nacional no puede absorber los títulos cuyos servicios precisan efectuarse en oro (Prebisch, 1921h: 146)

Los bancos ampliaban sus créditos formados por el «capital y los depósitos» (ibid., p. 147); obviamente «la tendencia que dominaba al gobierno, obtenía su triunfo definitivo por la aprobación por el Congreso, del Plan de Bancos Libres o Bancos Garantidos, redactado por el Poder Ejecutivo en septiembre de 1887» (ibid., p. 148): la crisis estaba cerca.

Cuando el desequilibrio del balance de pagos se incrementa en 1890, dice Prebisch, se reduce la capacidad para hacer préstamos y los servicios de la deuda no aminoran. Se generaliza entonces la «desconfianza» (ibid, p. 156) y la única alternativa repite el «paliativo» de generar emisiones inconvertibles que se «efectúan clandestinamente». Aunado a la crisis política cae el gobierno de Celman, «fiel exponente del despilfarro» (ibid), y con la caída de la casa bancaria Baring Brothers se conjura el estallido final del periodo con la revolución política.

Prebisch declara que la historia económica descrita no tuvo pruritos «académicos», más que el de «investigar la acción de los factores que aún perduran» y conocer la "génesis de muchos fenómenos actuales», y que creía se 
encontraría en un libro que se decía rendir homenaje al «método histórico que tanto impulso dio a la ciencia económica» (Prebisch, 1921h: 159); sin embargo, las páginas del doctor Piñero «son simples narraciones, en que los hechos importantes figuran en el mismo plano que los detalles insignificantes y las disposiciones legales atraen demasiado la atención» (ibid).

Finalmente, Prebisch realiza una breve descripción entre el viejo y el nuevo régimen en torno a las nuevas formas bancarias y crediticias:

Si en el siglo pasado las funciones bancarias y monetarias al ser ejercidas por institutos de emisión a la vez que de depósito y descuento han estado íntimamente ligadas, en lo presente, sin perder su interdependencia, se desarrollan en dos planos distintos. La cantidad de billetes en circulación ya no depende directamente de los establecimientos de crédito, sino del estado del balance de pagos. La caja de Conversión, única institución emisora, entrega billetes por oro u oro por billetes (prescindimos de la anormalidad actual), según la necesidad que el país tenga de importar o exportar oro; por manera que, sólo de esta forma, la circulación de billetes se expande o retrae. En cambio, en el régimen anterior, si bien los movimientos del balance de pagos influenciaban poderosamente la cantidad de billetes en circulación, la dependencia no era tan directa, automática, como bajo el sistema presente. Los bancos no estaban sujetos a la relación estricta que implica un exacto contravalor en oro por cada billete emitido, sino que podían lanzar billetes a la circulación, sin garantía metálica expresa [...] por esto al sobrevenir un desequilibrio en el balance de pagos [...] es necesario la exportación de metálico, y por tanto la inconversión de billetes (Prebisch, 1921h: 162-3).

Por lo mismo, Prebisch postula la apertura de la Caja de Conversión:

Actualmente, al ajustarse la emisión a un exacto respaldo en oro, la inconversión, de hecho, por el juego de factores económicos, no podría 
producirse. Es cierto que la masa de billetes sin garantía expresa, legado de las emisiones del siglo del pasado, da lugar a temores, y los temores a proyectos de reforma. Ya veremos cuán infundados son unos como otro. Asimismo, nos referimos a la inconversión actual, producto político y no económico. Que ambas funciones [bancarias y monetarias] [...] se desarrollen en diversos planos, no excluye la existencia, entre ellas, de un intricado plexo de acciones y reacciones. El aumento de billetes causado por la afluencia del metal amarillo, traído a su vez para saldar balances favorables, es base propicia para una expansión del crédito. El oro, en sí mismo o por medio de billetes, va directamente a las reservas de los bancos - que son quienes lo importan al país — o indirectamente, al ser depositado por el público después de haber circulado. Y al aumentar el coeficiente de las reservas se aflojan los resortes del crédito [...] Cuando ocurre un trastrueque en la situación [...] un desequilibrio en la balanza de pagos exige la salida de metal, las reservas bancarias comienza a devolver los billetes que otrora las alimentaran, disminuye la circulación, y acaece una restricción del crédito [...] En todo caso la conversión continúa, pero la disminución de los billetes [...] traen una crisis bancaria y comercial (Prebisch, 1921h: 163).

Todo lo dicho sobre la importancia de mantener cierta proporcionalidad entre el metálico y la emisión de billetes mantuvo vivo el reclamo original a Justo de que se debería pensar en un mecanismo alternativo para evaluar la evolución del valor o poder de compra de la moneda. Si bien en «Anotaciones sobre nuestro medio circulante» (Prebisch, 1921h) parecería que dicha discusión está fuera de lugar, Prebisch la recupera en una larga nota de pie donde subraya una distinción del vocabulario cuando habla del valor del oro, ya que su stock y su valor deben diferenciarse:

Nótese que decimos valor «metálico» del billete para diferenciarlo de su valor o poder adquisitivo, esto es su valor no en términos de oro, sino de los 
demás bienes porque se cambia. Los dos valores pueden marchar, a veces, en sentido contrario; depende del estado del balance de pagos y el mercado interno. a) Supongamos un país cuya circulación inconvertible no aumente, mientras los negocios se activan de tal suerte que cada billete acrecienta su poder adquisitivo; la baja de los precios estimula las exportaciones y disminuye las importaciones; el balance de pagos [...] se vuelve favorable, $y$ por medio del mecanismo de los cambios, el metálico es importado al país, disminuyendo su valor con relación al papel, esto es, el billete se valoriza en términos de oro, pudiendo llegar a efectuarse la conversión, y de poder adquisitivo. En este caso, los dos valores marchan en el mismo sentido. b) Puede suceder otro caso, [el argentino] en que, el balance de pagos se vuelve favorable y se producen importaciones de oro que acrecen el valor metálico del billete, pero no debido a los saldos favorables del balance comercial, sino a los del balance de préstamos (o sea el saldo entre las sumas que el país toma prestado y los servicios de los préstamos anteriores que tiene que pagar al exterior); en que el oro importado, a más de servir para la conversión de la emisión inconvertible existente (como pudo suponerse en el caso a), sea entregado a la circulación en forma de nuevos billetes convertibles; $y$ en que, a su vez, esta mayor circulación sirva de base para una expansión del crédito [...] Es decir que en el caso b) o los dos valores marchan en sentido contrario, o uno permanece fijo y el otro varía, en tanto que en el caso a) los dos valores marchan juntos (Prebisch, 1921h: 115).

Prebisch retorna a la problemática discutida por Justo (lo cita en Diario de Sesiones de la Cámara de Diputados, 23 de junio de 1920) sobre el «número indicador del costo de la vida obrera»: «calculando según la importancia que tiene en el presupuesto obrero cada uno de los renglones, y que se estableciera por la ley o en otra forma, el alza automática de los salarios, en proporción al alza del costo de la vida obrera» (ibid; 1921a: 194-195).

$\mathrm{Va}$ en el mismo sentido su siguiente trabajo, «Planes para estabilizar el poder adquisitivo de la moneda» (Prebisch, 1921a): «el valor o poder ad- 
quisitivo de este meta no es constante [...], su propio valor cambia, $[\ldots]$ por consiguiente» no es «el instrumento ideal de las transacciones» (Prebisch, 1921a: 176). La idea de contrarrestar sus fluctuaciones se considera como «descabellada y peligrosa» (ibid), «sin embargo, la observación estadística de los fenómenos económicos demuestra que la moneda cambia continuamente de poder adquisitivo» (1921a: 176).

Es cierto que Prebisch tradujo la obra de Enrico Barone (Principii di Economia Politica) al español, pero el libro más citado es el de Pantaleoni (Principios de economía pura). ${ }^{21}$ Pero, finalmente, es Fisher quien pareciera ser el héroe intelectual en la mayoría de sus elaboraciones teóricas de la época. Sin embargo, el giro teórico en el plan de Fisher para estabilizar el poder adquisitivo de la moneda lo deja defraudado cuando éste retira la importancia de «la teoría cuantitativa de la moneda» (Prebisch, 1921a: 206).

En «Planes para estabilizar el poder adquisitivo de la moneda» (1921a) insiste en que «el valor o poder adquisitivo de este metal no es constante [...], su propio valor cambia $[\ldots]$ por consiguiente» no es «el instrumento ideal de las transacciones» (Prebisch, 1921a: 176). La idea de contrarrestar sus fluctuaciones se considera como «descabellada y peligrosa» (ibid.)ः «sin embargo, la observación estadística de los fenómenos económicos demuestra que la moneda cambia continuamente de poder adquisitivo» (1921a: 176).

Es precisamente la teoría cuantitativa la que explicaría el «proceso exacto» por medio del cual, además de «aumentar o disminuir la cantidad de oro contenida en cada unidad monetaria» (o sus signos), tendrán que alterarse también «el número de unidades circulantes», para ejercer una acción «sobre el nivel general de precios», por «eso, cuando se cambia» la unidad del peso de oro de la moneda, basado en el plan de Fisher («directos», «indirectos»o «mixtas»), se cuenta «con los medios» «para alterar la cantidad de billetes en circulación y afectar por consiguiente a los precios» (Prebisch, 1921a: 206).

121/ Sobre la importancia del pensamiento italiano en Buenos Aires: Fernández López (2000b, 2001, 2002, 2008); sobre Fisher Fernández López (2000a) y Semper (2010). 
El hecho de que cada unidad monetaria contenga, virtualmente, más o menos cantidad de oro que antes, no tiene acción alguna sobre el nivel de los precios, mientras la cantidad de certificados en circulación sea la misma [...] Es por esto que el retorno del número indicador a su nivel normal sólo se conseguiría expandiendo o ratificando la circulación de certificados, para lo cual propone Fisher dos sistemas, el directo y el indirecto - dividiéndose este último en otros más - que están en relación con el sistema de reserva que se adopte (Prebisch, 1921a: 200-201).

Para esta fecha, Prebisch demuestra que su defensa del valor de la unidad de cuenta supuso antes haber despachado tanto la teoría según la cual toma como medida el «trabajo socialmente necesario para producir» ciertos bienes (Prebisch, 1921a: 193), así como aquélla que se sustenta en la subjetividad de quienes los producen.

Se requiere construir, entre los elementos del plan de Fisher, así como el de Bunge, sobre el coeficiente de corrección de la moneda, cierto número indicador y conocer el número de artículos que se utilizarían para la unidad bienes-oro en cuestión. Fisher argumenta que se tiene que utilizar los precios que rigen al por mayor de la canasta básica que se haya utilizado. Bunge busca encontrar lo que llama el «mayor valor». Prebisch sostiene que «son las variaciones del nivel general de precios» y que responde a causas «generales» el mejor mecanismo para tal efecto debido a que «pueden servir de base a la apreciación exacta del mayor valor; es lógico que un número indicador en el que los productos agrícolas formasen la mayoría o tuviesen indebido peso nunca permitiría la averiguación del mayor valor, pues éste, a su vez, proviene del ascenso de esos mismos precios» (1921a: 195).

De todas maneras, pareciera ser que el Fisher de The Purchasing Power of Money, posterior a Stabilizing the Dollar, ya no defiende ni requiere necesaria la teoría cuantitativa de la moneda para explicar el plan de estabilización del poder adquisitivo. Sin embargo, Prebisch ve con gran «extrañeza» que Fisher 
recupera la tesis cuantitativa de la moneda cuando quiere argumentar la posibilidad de comprobar que la mudanza en el «peso del peso (\$) cambiará por sí solo el número de pesos en circulación». Insiste que si bien la teoría en cuestión lo supone, esto depende de una acepción no «rígida», «que la cantidad de moneda hace variar, proporcionalmente, a los precios, sino que todo influjo de moneda hace subir los precios y todo reflujo los hace bajar» (1921a: 206). Pero de hecho...

[...] las dos iniciativas [Justo y Bunge] argentinas cayeron en el vacío, seguramente por su falta de mayor difusión, principalmente, entre los sindicatos obreros y patronales, que en otros países adoptaron planes de ajustamiento de los salarios, según fluctuaciones de costo de vida. Sin embargo, existe, en un proyecto de ley de salario mínimo presentado a la Cámara de Diputados en las últimas sesiones del periodo ordinario de 1920, por el doctor Anastasi, una disposición referente a las variaciones de este salario, según las fluctuaciones del costo de vida denotadas por los números indicadores; este proyecto constituye la primera iniciativa de legislar sobre estas cuestiones (1921a: 206).

Desde el segundo año universitario, Prebisch trabajó como ayudante de trabajos prácticos del director del Seminario de Investigaciones y desde entonces logra independizarse de las remesas enviadas por su padre. A fines de 1922 surge su primer empleo con un holgado salario ${ }^{22}$ en las entrañas de la oligarquía ganadera: la Sociedad Rural Argentina que tenía interés en fundar una oficina de estudios. Fue a través de la recomendación de Lobos que sus autoridades se acercan para ofrecerle un empleo. No obstante, como veremos a continuación, la diáfana narrativa de Prebisch en su primer informe, «Información estadística sobre el comercio de carne vacuna» (Prebisch, 1922a), no sirvió para mucho.

122/ Ganaba en la facultad 200 pesos, que «era mucho por esa época». Prebisch no respondió a la pregunta de «¿cuanto quería ganar?», pero le dieron 800 pesos (Magariños, 1991: 52). 
La insistencia de otros hacendados — quienes se hicieron cargo de la directiva de la Sociedad Rural y buscaban formas de intervenir los frigoríficos- no podía fundamentarse con los resultados del informe. La crisis y la declinación de los precios no se debían a ningún tipo de control monopólico del pool de los frigoríficos, no obstante la existencia de un acuerdo entre ellos para organizar la entrega y la venta de los productos cárnicos en el mercado de Smithfield en Londres, el cual a su vez tampoco controlaba la oferta.

En «Información estadística sobre el comercio de carnes», Prebisch (1922a) apabulla al lector con cifras y gráficos que hasta la fecha nadie había logrado elaborar. La obtención de la información necesaria sobre los precios y su elaboración por parte de los frigoríficos en el mercado de Liniers en Buenos Aires fue todo un vía crucis: explicándole al administrador que sin esa información sería despedido de su trabajo. Prebisch destaca que 40\% de la carne vacuna importada al Reino Unido (1922a: 237) provenía de Argentina, mercado que absorbía en 1921 el 94\% de la producción mundial por entonces exportable.

Por otra parte, nos explica cómo elabora los números indicadores ${ }^{23}$ que son una «expresión muy cómoda, a que se llega por un sencillo procedimiento estadístico» (1922a:240). Los datos reflejan un volumen «físico» de exportacio-

${ }^{123 /}$ Dice: «Así, en lugar de decir que el precio de la libra de carne vacuna chilled en el mercado de Smithfield era 5.125 peniques en 1913, 12 en 1917 y 12,125 en 1920, diremos, tomando como "base" de comparación la cifra de 1913, que por los precios han variado según lo indican los números indicadores respectivos, a saber:

$\begin{array}{lll}\text { Años } & \text { Operaciones } & \text { N.I. } \\ 1913 & 5,125 & =100 \\ 1917 & (12 \times 100) / 5,125 & =234 \\ 1920 & (12,125 \times 100) / 5,125 & =237\end{array}$

[...] Hace lo mismo cuando describe el «promedio ponderado»: «Pero como Sudamérica por una parte, y Australia y Nueva Zelandia por otra, no concurren en las mismas proporciones en el mercado británico, para obtener un término medio de ambos, hemos multiplicado cada uno de ellos por la proporción en que la carne que representan entra en el conjunto de la importaciones, y dividido la suma de los dos productos así obtenidos, por la suma de las proporciones consideradas (el promedio así resultante se designa en estadística como "promedio ponderado"»(Prebisch, 1922a: 240, 253-254). 
nes creciente (pendiente positiva) y un nivel de precios en declive, entre 1921 y 1922. Diseña, para tal efecto, los vocablos volumen físico y volumen económico del consumo. El consumo dentro de ciertos «límites» es «elástico», «susceptible de aumentar o disminuir, según la mayor o menor cantidad de dinero que los individuos puedan destinar para su adquisición» (1922a:251). Los consumidores van dejando la carne «congelada» por la «chilled» a medida que los precios declinan, que explica el creciente predomino de dicho rubro en las exportaciones del volumen físico. Cuando compara la evolución de precios entre el mercado de Smithfield y el de Liniers, entre 1921 y 1922, el «descenso medio de los precios fue mayor en el primer mercado que en el segundo» (1922a :291); fenómeno que Prebisch articula al descenso de los valores, como en «toda crisis» (ibid.: 301). Termina su informe asentando que no tenía como objetivo establecer «conclusiones generales» (ibid.: 302), solamente dar a conocer «hechos concretos» (ibid.: 303) con una clara «comprobación experimental».

En síntesis, fue el diputado Matías Sánchez Sorondo quien solicitó expresamente a Prebisch recabar información para probar «que el mercado de Smithfield es una pantalla simplemente» (Prebisch, 2006), algo que el informe de Prebisch no podía defender (Prebisch, 2006):

Triunfaron, como te puedes imaginar, los violentos, que querían apoderarse de los frigoríficos, como un loco Pagés, a raíz de lo cual me expulsaron. Fue mi primera expulsión y salí con gran fastidio, por supuesto, por la injusticia, porque no se me escuchó ni se me permitió explicar. Y me fui a Tucumán y allí escribí las «Anotaciones sobre la Crisis Ganadera».

Al ser cesado, Prebisch escribió en Tucumán, furiosamente: «Anotaciones sobre la crisis ganadera» (Prebisch, 1922f), ${ }^{24}$ subrayando sus hallazgos en los meses antes de su primer informe. Inicia con una fuerte diatriba:

\footnotetext{
124/ Lo firma Raúl Prebisch como «ex director de Estadística de la Sociedad Rural Argentina».
} 
Cerca de dos años han transcurridos desde los comienzos de la intensa desvalorización del ganado vacuno sin que se haya tomado medida alguna de carácter positivo, pese a la grita del gremio de hacendados y al diario repiqueteo de los proyectistas. [...] el análisis objetivo de los hechos concretos cede el lugar, frecuentemente, a las afirmaciones antojadizas y la vacía elocuencia, cuando no al manejo arbitrario de las estadísticas. No es de extrañar, sin embargo, la gran simplicidad en que los ganaderos argentinos han desarrollado siempre sus negocios, les despreocupó casi por completo de la observación y estudio de las condiciones económicas en que se efectuaban. [...] era profundo el desconocimiento de los productores del país, del mercado británico que absorbía casi la de las exportaciones de carne argentina. Sin embargo, algunos ganaderos parecen refractarios a este análisis. Convencidos - como nosotros- de la existencia de un «pool» entre los establecimientos frigoríficos, le suponen con míticos contornos. Y la idea de una entidad omnipotente, capaz de manejar los precios y torcer el comercio a su antojo, es mucho más accesible a la simplista y aletargada mentalidad pastoril, que la explicación que fluye de los fenómenos concretos, de suyo complejos (Prebisch, 1922f: 304-305).

El eje central de la narrativa toma como su guía una serie de propuestas que emergen de un discurso por el «celebrado conferencista» (1922f: 306), el «señor Pagés», y a nota de pie de página dice:

Es de lamentar que el doctor [Matías] Sánchez Sorondo se haya impregnado tan fácilmente de esta fofa argumentación [...] «Quiere decir entonces que no es exacto que tenga aquí su imperio la ley de la oferta y la demanda. Los efectos de esta ley son bien conocidos: a mayor demanda mayor precio, a mayor oferta, menos precio. Aquí en el mercado argentino hemos tenido más demanda el año 1922, y hemos tenido me- 
nor precio el mismo año 1922. Hay una alteración profunda de las leyes económicas» (Prebisch, 1922f: 307).

Según Pagés, no puede haber aumento del consumo del carne vacuna argentina en Smithfield al mismo tiempo que sucede un «descenso de las cotizaciones» (1922f: 307), lo cual Prebisch refuta dando cátedra sobre las nociones de la oferta y la demanda. «A la luz de la teoría y la práctica», la exposición del «poderoso hacendado» «resulta deleznable» (1922f:307).

La primera, basada en la experiencia, nos enseña que el juego de la oferta y la demanda, y su resultado, el precio, constituyen, en la realidad concreta, una completa e inestable urdimbre de acciones y reacciones. Que la demanda de un artículo y su consumo sean más intensos, no significa siempre que los precios hayan de subir. En primer caso, dado un determinado nivel de cotizaciones y una oferta invariable, si la demanda aumenta, y los otros factores permanencen los mismos, dicho nivel ascenderá, es así que la mayor demanda trae consigo precios más altos. En un segundo caso, para no abundar en otras hipótesis familiares en los textitos de economía política, el descenso de los precios estimula la demanda, la hace más intensa; en efecto, dado determinado nivel de precios y una oferta creciente, y un supuesto que los otros factores permanezcan los mismos, para que los conusmidores absorban mayor cantidad del artículo considerado que lo acostumbran, habrá que ofrecérselo a precios más bajos; tales precios más bajos son el acicate de una demnada más amplia y profunda (Prebisch, 1922f: 307). ${ }^{25}$

125/ No es nada irónico, por el vuelco que tomará el pensamiento de Prebisch en los años que siguen, el hecho de que conjuga el prístino vocabulario de la oferta y la demanda, o del «mercado», cuando de hecho la problemática discutida trata las distintas relaciones de poder entre distintos sectores productivos internos y externos. 
Además, no obstante la baja de precios, «lo pagado [en volumen económico] por el chilled en 1921 fue mucho mayor que en 1920 [...] En el año 1922, la evolución del mercado continúa en el mismo sentido» (1922f: 308), proceso mediante el cual la chilled va aumentando su participación a «expensas del congelado» ${ }^{26}$

Es tal la dominancia de la carne argentina en Smithfield, y por tanto una excesiva oferta de carne chilled, que «Australasia nos acusa insistentemente de haber desalojado su carne congelada, al producir un "glut" en el mercado» (1922f: 310). Esto da pie, incluso, a que Prebisch especulara que, de lo contrario, «los precios se hubiesen mantenido firmes» $y$ entonces «cuál hubiese sido el efecto de la reducción de las exportaciones argentina sobre nuestro mercado productor?»:

Fiel al dogma del poder místico del «pool» de frigoríficos, el hacendado Pagés, a más de afirmar sin demostración alguna la existencia de hechos problemáticos, rechaza indignado la tesis anterior, que ya formuláramos en el folleto citado [Prebisch, 1922a] de la Sociedad Rural Argentina (ibid).

Dado el modo de «discurrir» de Pagés, que consiste en elaborar una serie de interrogantes de manera retórica para responder a todas en negativa remitiéndose al «folleto» de Prebisch, éste a su vez responde una por una.

Entre las refutaciones que realiza Prebisch, es de señalar que tanto en el mercado local ${ }^{27}$ como en Smithfield el consumidor también se beneficia de la baja de los precios. Sin embargo, la «fecunda intuición» del «hacendado Pagés» insiste en la...

126/ En contraste con el producto vacuno congelado, el chilled es mucho más fresco y no puede transcurrir mucho tiempo antes de su consumo.

127/ «Un hecho análogo puede observase en nuestro país. Los precios al por mayor de la hacienda para el consumo han descendido en el mercado de Liniers; asimismo los que paga el consumidor, pero en menores proporciones. El hecho fundamental es que la baja más o menos intensa de las cotizaciones al menudeo ha permitido el aumento del consumo "per cápita" y ha ayudado a descongestionar el mercado» (nota a pie de página, 1922f: 314). 
Confabulación entre los frigoríficos y los «jobbers o comerciantes mayoristas que adquieren la carne que estos últimos importan en Smithfield». De tal suerte que este mercado sería simplemente una pantalla, un instrumento de que el «trust de la carne» se serviría para engañar, y las cotizaciones a que se efectúan los negocios serían absolutamente ficticias, y no las cotizaciones reales que rigen para el comerciante independiente (1922f: 314).

Y, sin embargo, el comisionado encargado de estudiar el funcionamiento del mercado señala que los comerciantes mantienen su independencia del lugar de donde compran la carne y a Smithfield puede acudir cualquier comprador/vendedor. En síntesis, dicho mercado se considera «libre» (1922f:314).

Prebisch realiza una historia sobre los hechos históricos que dan ciertos cambios al comercio de carne argentina: la aparición de capitales estadunidenses, en 1907, rompen con los acuerdos convenidos entre los frigoríficos «ingleses y anglo-porteños». Localmente, empezaron a elevar precios de compra de la carne de vacuna para su exportación y no llegaron necesariamente a un acuerdo con los anglo-porteños sobre los volúmenes físicos para exportar a Smithfield. Eso produjo una baja en la tasa de ganancias en dicho sector y para 1912 resolvieron conformar un «pool». A cada uno de los frigoríficos se le acordaban los volúmenes físicos específicos que podían embarcar/exportar al Reino Unido y reducir la competencia de las empresas en la compra del ganado local. No obstante, el precio de la carne vacuna «se mantuvo firme» (1922f $\$ 321)$. De todas maneras, ello significó que la acción del «pool» estabilizó el derrumbe de los precios en 1912. La hipótesis de Prebisch es, que de haber sucedido lo contrario, los incrementos sustanciales de las exportaciones de chilled hubieran inundado el mercado y reducido los precios en Smithfield. Para 1913, el «pool» no se renovó y los precios locales se elevan y las compañías anglo-argentinas «su grita». Prebisch dice:

Sea como fuere, el hecho que merece subrayarse es que el «pool» o entendimiento de los frigoríficos se impuso para evitar la caídas de los 
precios en el mercado del consumidor — caídas determinadas por las importaciones excesivas-; y para limitar la competencia y por lo tanto la elevación de los precios en el mercado productor, más allá de ciertos límites. $\mathrm{El}$ «pool» se presenta, de tal suerte, bajo un doble aspecto. En cuanto evita la depreciación de un producto argentino en el extranjero, es beneficioso para la economía nacional. En cuanto, bajo la protección de una competencia limitada, presiona sobre el valor del ganado, es perjudicial. No puede, por lo tanto, contemplársele con un criterio absoluto: así como en ciertos momentos puede aprovecharse del productor, en otros el «pool» resulta una verdadera necesidad, tanto para las empresas que lo forman, cuanto para aquél. Es así que el problema no está en destruirle - si fácil fuere el evitar que pocas empresas se entendieran expresa o tácitamente- sino en reforzar su aspecto útil y evitar los abusos que pudiera traer (Prebisch, 1922f: 322).

Pero a la retórica del hacendado Pagés, «¿Quién dispone, pues, del volumen físico y económico del mercado?», Prebisch responde a pie de página para inhibir un poco las consecuencias auditivas a que da lugar las alocuciones repetidas de «Señor Pagés»:

Sin duda alguna, el «pool» al limitar la competencia, limita los precios del ganado en nuestro país. Ello no quiere decir, sin embargo, que «disponga» del volumen físico o económico de las transacciones en el mercado británico; ya hemos dicho que toda combinación está condicionada por factores de hecho; productores o vendedores, libres o combinados, pueden actuar sobre el volumen físico, al aumentar o restringir la cantidad de mercaderías que ofrecen: pero no pueden manejar al consumidor que absorbe el mayor volumen físico si se estimula con precios bajos. Las exclamaciones, ¡Señor Pagés! ¡Señor Pagés!, resultan con frecuencia juegos de palabras (nota de pie de página, Prebisch, 1922f: 322). 
La descripción histórica de la evolución de la «industria madre» (Ibid: 328), hasta el periodo de la crisis en 1921, supone tener en cuenta que las «cantidades anotadas» a la baja del volumen físico son el «complejo resultado de estas acciones y reacciones»: «el debilitamiento de la demanda externa, y el aumento de la oferta en nuestro mercado interno, los precios bajan; lo que a su vez reacciona sobre la demanda, y la estimula. [...] La mayor oferta de ganado en el año 1922, con respecto a 1921, fue absorbida en gran parte por el consumo interno a merced del descenso de los precios (Prebisch, 1922f: 332-333-334).

En síntesis, según Prebisch:

El descenso de los valores de la carne y el ganado vacuno hubiese acaecido también en un régimen absoluto de libre concurrencia entre los frigoríficos, y que, debido al «pool» — que limita la competencia- esos últimos estuvieron y están en condiciones de intensificar la baja de precios [y] mientras el gobierno no se decida a contralorear la industria de carnes y competentes técnicos oficiales estudien el problema de las ganancias, en los mismos frigoríficos, por cada animal faenado, toda apreciación sobre la materia es susceptible de grandes errores (Prebisch, 1922f: 339).

Por lo mismo, Prebisch ofrece algunas opiniones sobre la «ortopedia» que requiere la ganadería. Pide intervención del Estado dada la incapacidad de los ganaderos de organizar sus ventas. A su vez, dada la existencia del «pool» de los frigoríficos se impone una investigación, sobre los costos/precios mínimos y máximos y su legislación:

Sin pretender entrar en detalles, nos parece que un sistema satisfactorio para llegar a este precio mínimo elástico, fuera pagar al ganadero un precio evidentemente bajo cuando vende sus haciendas, y abonarle más tarde primas variables de acuerdo a la cotización que la carne proveniente de aquéllas hubiese obtenido en el mercado británico y a las alteraciones 
que habrían sobre venido en los costos de elaboración y de transporte (Prebisch, 1922f: 348).

A pie de página agrega: «A los efectos del precio mínimo, para no perjudicar a ninguna empresa, debiera tomarse como base el costo unitario de elaboración más alto - el "costo marginal" de los economistas» (ibid). Por lo tanto, ello establecería cierta tasa de ganancia de los frigoríficos y no habría razón de preocuparse por la acción del «pool» sobre las exportaciones.

Las «Anotaciones sobre la crisis...» no podrían finalizar sin antes ofrecer las admoniciones a las que tenía acostumbrados a todos: «la crisis ganadera ha turbado el letargo de los hacendados argentinos, y tal vez contribuya poderosamente a que su instinto de clase -incoherente, desorientado y negativo las más de las veces - se transforme en clara conciencia de sus intereses económicos» (Prebisch, 1922f: 349). El instante que terminaba sus notas ya tiene conocimiento que han aparecido los memoriales de los frigoríficos presentados a la Comisión Especial de Asuntos Ganaderos de la Cámara de Diputados de la Nación, que según su interpretación, habiendo examinado los mismos «hechos», llegaron a similares «apreciaciones sobre el precio mínimo» y su construcción (Prebisch, 1922f: 349), que él desarrolló en su trabajo.

No será la última ocasión en que las pasiones de sus confrontaciones con la oligarquía ganadera dejen un derroche de reflexiones y críticas a su proceder «pastoril». Durante 1923 podemos observar un periodo relativamente improductivo en términos de los ritmos de trabajo que Prebisch acostumbraba. Entonces escribe «La sociología de Wilfredo Pareto» (1923c), «A propósito de la primera conferencia del profesor Jase» (1923b) y «La Caja Internacional de Conversión. El proyecto monetario del Dr. Fres» (1923a).

Vale destacar que en su presentación, en octubre de 1923, de la «sociología» de Pareto, Prebisch cierra su exposición con un toque de humildad inusitada:

He expuesto la impresión recogida por mí en una lectura desordenada de la Sociología. Dudo mucho de su fidelidad y sobre todo de su clari- 
dad. Pero estoy contento de estas líneas: al escribirlas se ha afirmado cada vez con más intensidad en mí la intención de estudiar sistemáticamente la obra del sabio maestro de Lausana (Prebisch, 1923c:373).

Del texto que trata la idea de una «caja de conversión» a nivel internacional para el intercambio internacional, Prebisch encuentra varios problemas. Uno de ellos tiene que ver con las asimetrías que existen entre los que poseen gran parte del oro mundialmente y los poderosos que nunca consentirían en que este sea «aguado» (1923a: 358) con expansiones de la unidad de cuenta («ases»), puesto que la:

Emisión de «ases» sin su íntegro respaldo metálico, tendría el mismo efecto sobre el poder adquisitivo de este último, que el que, en diversas épocas históricas, tuviera el gran aflujo de oro subsiguiente al descubrimiento de nuevas minas productivas [...] [y además] Todos los países de moneda envilecida aspiran a llegar de nuevo al patrón oro. ¿A qué entonces manosearle? (1923a: 358-359).

Dejamos al final el comentario de su defensa de la pertinencia de la primera conferencia del «profesor Jèze» en la Facultad (Prebisch, 1923b), ya que, a la postre, nos encontramos que fue su publicación la que suscitó una reacción de alguien allí aludido y que nuevamente producirían su despido, en esta ocasión, de tareas gubernamentales. Sucede que según el recuento de Prebisch, alrededor de 1923 recibe una carta del entonces ministro de Hacienda para que lo visite a su oficina. Allí se enteraba que necesitaba investigar aquellos países similares al argentino para elaborar un «impuesto a la renta» (Magarinos, 1991: 54). Nuevamente, fue a través de las relaciones familiares del doctor Lobos que su nombre llega recomendado. ${ }^{28}$

${ }^{128 /}$ «Don Rafael era padre de una niña muy linda con la cual se había casado el hijo mayor del doctor 
Efectivamente, Prebisch viaja a Nueva Zelandia y después a Australia, llegando a Sídney el primer día de enero de 1924 para realizar sus investigaciones sobre el sistema impositivo. También dedica su tiempo para conocer el sistema estadístico y sus máquinas de tabulación Hollerith (Prebisch, 2006). Pero Prebisch no se traslada sencillamente bajo una «misión de estudio», ya que en su artículo «Establecimiento de nuestra administración financiera sobre bases comerciales» (Prebisch, 1924b) firma como «Ex-Secretario de la Comisión de Presupuesto y Finanzas del Ministerio de Hacienda», lo cual significa que éste fue el primer puesto gubernamental que ocupó. Veremos a continuación los cambios gubernamentales y las verdaderas razones de su rescisión en plenas tareas de «estudio» en Australia.

Fueron precisamente las alusiones a un articulista que firmaba «S.O.» (Prebisch,1923b: 360), en su «defensa del profesor Jèze», lo que le costó el empleo:

La argumentación principal del articulista [...] estriba en que el señor Jèze, recién llegado a la Argentina, «ajeno hasta ayer» a los problemas de nuestra vida financiera, mal podría abordarlos con éxito [...] ilusorio esperar gran cosa de su improvisado curso sobre las «finanzas argentinas» (Prebisch,1923b: 360).

Prebisch, además de dar explicación sobre su nada improvisada visita, remata:

El lector que no conozca el significado de la obra de Jèze en la evolución de los estudios financieros, y su carácter estrictamente objetivo, el que ignore que la obra de Jèze, tamizada severamente a través del método ex-

Lobos, Marcelo Lobos [...] [el Ministro] me dijo: "Joven, me complace conocerlo. El doctor Lobos, mi consuegro, me ha sugerido su nombre” (Magariños, 1991: 54). 
perimental, representa una reacción vigorosa contra la metafísica financiera, en que aún se deleitan estérilmente algunos profesores de finanzas, para escapar el trabajo sistemático, paciente y a veces infructuoso que requiere la observación de los hechos concretos; el lector que no esté al corriente de estas cosas, después de enterarse del artículo referido, se ha de sentir impulsado a confundir al profesor Jèze entre los tantos conferencistas de ultramar, que, ayudados por la gracia y persuasión de su palabra fluida, vienen a encontrar un éxito fácil entre nosotros [...] Estoy seguro que la intención del articulista está muy lejos de esto (Prebisch, 1923b:360-361).

El articulista señalado era nada menos que Salvador Oria, que además de haber sido su profesor, quedó ocho meses más tarde como subsecretario de Hacienda cuando Víctor M. Molina remplaza a Rafael Herrera Vegas como secretario de Hacienda. Dudamos que Prebisch no supiera de la identidad del articulista. ${ }^{29}$ Despedido en pleno «estudio», vía telegrama, no le impidió seguir sus investigaciones que le serían muy útiles para elaborar el proyecto de reforma de la oficina de estadísticas de la nación en 1925: «Anotaciones a la estadística nacional» (Prebisch, 1925a) y, subsecuentemente, concursar y ocupar el cargo de la subdirección de Estadística de la Dirección General de Estadística de la Argentina en 1926; así como, unos años más adelante, elaborar el decreto de los «Impuesto a los réditos» (Prebisch, 1932a).

A su retorno al país, después de su «primer viaje», vía Europa, marzo de 1924, Prebisch es «bautizado» por el periódico La Prensaः «Viajes de Turismo pagados por el gobierno. Joven que acaba de egresar, sin ninguna experiencia [...] Es un dilapidar del dinero. Así fue el artículo» (Magariños, 1991: 54). No obstante, las actividades y publicaciones de 1924 desmienten mucho de

129/ Obviamente no ayudó a Prebisch el hecho de que el propio Jèze lo haya citado para defenderse en la compilación y publicación de sus conferencias (Jèze, 1923: 25). 
esas acusaciones: en primer lugar, realiza un informe — «Primer informe del Dr. Raúl Prebisch sobre sus estudios financieros y estadísticos en Australia», (1924a) — ${ }^{30}$ dirigido al nuevo secretario de Hacienda, detallando sus actividades, entre las que cuentan: «Determinación de la capacidad imponible. Método australiano de promedios» (1924c) y «Aclaraciones al proyecto de colonización del Poder Ejecutivo» (1924d), ${ }^{31}$ así como la publicación de «Establecimiento de nuestra administración financiera sobre bases comerciales» (1924b). En el artículo final se plantea una reorganización de la administración «financiera sobre bases análogas a las de la administración comercial privada» (ibid, 374), señalando que se centralice la administración financiera en la figura del ministro de Hacienda $y . .$.

En cada departamento o repartición exista un funcionario técnico, de carácter no político, designado por el ministro correspondiente y res-

130/ «Aunque la resolución por la que se me declaraba cesante cablegráficamente me fue comunicada a fines de marzo [1924a], resolví, sin embargo, quedarme hasta el 17 de abril para cumplir el plan de investigaciones que me había impuesto. De lo contrario, el fracaso proveniente de la falta de tiempo hubiese sido interpretado como confirmación de lo que un diario de la capital decía a propósito del decreto del anterior Ministro: estos envíos al exterior "en último análisis no resultan más que pretextos para viajes recreativos a costa del erario"» (ibid, 1924a: 403)

131/ Firmado como «egresado» de la Facultad de Ciencias Económicas de la Universidad de Buenos Aires, Prebisch defiende el proyecto que tiene mucho para desconcertar al «romanticismo académico ansioso de creaciones exuberantes: responde empero, a exigencias circunstanciales y a las enseñanzas de la experiencia colonizadora en países como Australia, Nueva Zelandia, se asemejan a la Argentina en su estructura económica» (1924d: 393). Así como azuza al parlamento que «no es precisamente por su actividad y celo público lo que conciben los teóricos de la "ciencia constitucional". Cuanto más largo y elaborado es un proyecto, tanto más se dilata y entorpece su trámite legislativo, y pero se desarticula su texto» (ibid.). También se lamenta del medio ambiente gubernamental: «A cada tentativa de reforma agraria en nuestro país, la agitación de las ideas y el comentario de las leyes extranjeras, enriquecen copiosamente la literatura sobre el problema. Contrasta con la efervescencia de palabras con la acción efectiva, sofocada en un trámite legislativo poco diligente, desvanecida por la influencia de los intereses en que la gran propiedad apuntala. Mientras tanto, la fisonomía de nuestras campañas se modifica con lentitud. Produce la tierra, aunque en malas condiciones; y el trabajador rural no se arraiga en ella para constituir las poblaciones vigorosas» (ibid.). 
ponsable directamente ante el mismo [...] se reglamente la carrera administrativa y se establezca la competencia como requisito para el ingreso al empleo público y la promoción del mismo (Prebisch, 1924b: 375).

Pero antes de zarpar hacia Argentina desde Australia, algo que tuvo que haber agradado mucho a Prebisch fue la invitación por parte del secretario general del Partido Liberal Georgista para dar una conferencia en el Henry George Club de Melbourne — realizada en inglés_- titulada «El problema de la tierra» (1924a), donde pudo, una vez más, describir las inequidades de la organización del campo y los hacendados ausentes.

Algunas pequeñas zonas florecientes, intensivamente bien cultivadas, constituyen la excepción en este aspecto del cultivo extensivo de grandes áreas [...] Pero en la Argentina el poder político de los grades terratenientes es todavía tan grande, que ellos impiden la aprobación de leyes contra sus intereses y consiguen mantener obstáculos a la ejecución de ciertas leyes que (como la «ley del hogar», proyectada hace muchos años a la manera de los Estados Unidos) intentaba establecer una población permanente sobre la tierra [...] Ellos impiden la aprobación de una ley nacional de impuesto sobre el mayor valor. Ellos pagan actualmente seis milésimos del valor nominal de la tierra, pero ese valor es mucho mayor que el valor verdadero. Es decir, que la contribución del propietario de tierra al tesoro nacional es muy pequeña en comparación con los enormes recursos que ellos reciben de su privilegio territorial. La inmigración fue preconizada con el fin de poblar el país. Pero, como ustedes pueden imaginar, esa intención falló. A causa del poder de los grandes terratenientes [...] La acumulación del valor no ganado de la tierra en un número de manos relativamente pequeño (Prebisch, 1924:378-379-380).

Por lo antes mencionado y por lo que sigue, vale la pena ubicar la evolución personal de Prebisch. Creemos que de las «confesiones» autobiográficas 
realizadas en sus diversas entrevistas (Magariños, 1991; Prebisch, 2006), podemos extraer que se «recibe» como contador público a fines de 1922, pero él no se considera «egresado» de la facultad hasta 1924. Es entre 1924 y 1925 que Mauricio Nirenstein y Luis Roque Gondra deciden incorporarlo como profesor de la Facultad (Prebisch, 2006):

Decidieron mandar una nota al Consejo Directivo de la Facultad proponiendo mi nombramiento de profesor titular y citaron un precedente del año 1860 del doctor Pirovano, que fue nombrado profesor de la Facultad de Medicina sin concurso. ¿Qué pasó entonces? Me exigieron que yo terminara mis estudios y me darían la cátedra.

La respuesta curiosa de Prebisch no explica que para concursar se hubiera requerido el grado de doctor. Sucede que Prebisch nunca obtuvo el grado de doctor (carrera de cinco años) porque no presentó la tesis al final. No sorprende su desinterés: en parte él ya había denostado el nivel académico de la facultad y de sus profesores.

¿Pero acaso no es lógica esta complacencia en profesores incapaces de dirigir un seminario, o que se desalientan al menor obstáculo? Es que estamos impregnados aún del viejo concepto de que las universidades son máquinas laminadoras de doctores. Salir con un título bajo el brazo es la suprema aspiración de muchos, no importando la insuficiencia de la preparación con que se sale. A este respecto, la posición de nuestra facultad no es de las peores; el título de Doctor en Ciencias Económicas es un acicate más débil que el de Doctor en Derecho o en Medicina, y la ventaja profesional, inherente al mismo, es ínfima en relación a la de estos últimos. Todo en nuestra carrera depende de la aptitud personal de los que la cursaron. Lógico sería entonces concluir de esto, que los que abrazan el estudio de la Economía van guiados por fuerte vocación; más no es así [...] muchos de los [...] que han entrado y entran en nuestra 
facultad, lo han hecho por encontrar casi herméticamente cerradas las puertas de las otras facultades (1921c: 65-66).

Ahora veamos lo que dijo entonces sobre la función de la tesis:

Un fiel reflejo de lo que antes hemos expresado, a saber que la reforma universitaria de hecho aún tiene que efectuarse, y que en el fondo el conjunto universitario sólo ha sido rasguñado por el movimiento de renovación, lo constituye, a nuestra manera de ver, un reciente pedimento elevado al consejo directivo sobre la supresión de las tesis. De seguro que no se fundamenta en la falta de materiales para hacer el trabajo, ni en la carencia de objetivos, pues pocos egresados se ven ante un campo tan inexplorado y desconocido como los diplomados en Ciencias Económicas. La causa es otra; se hace la observación que la tesis, actualmente, no tienen valor alguno; en lo que estamos en absoluto de acuerdo. Salvo raras excepciones, los trabajos de tesis son pura hojarasca. Pero, ¿̇ignifica ello que debemos pedir a las autoridades que sean más exigentes sobre su contenido o que las supriman? Lo primero podría hacerse en cierta escala rechazando de plano ciertas tesis que no respetaría aun el más profano en cuestiones económicas, o cuyo material es demasiado elemental y empírico para que pretenda representar la culminación de estudios superiores (por ejemplo, contabilidad ganadera). Pero más no cuadraría exigir, en vista de que, en general, el egresado sale sin aptitudes para hacer una investigación seria y meditada, dado el carácter de la enseñanza que ha recibido. Lo segundo, que es lo que se solicita, equivaldría a querer borrar una de las manifestaciones de un mal general, sin preocuparse mayormente de las causas internas que lo originan: pésimo e inconducente sistema. La supresión de las tesis nos evitaría la tarea de hilvanar rápidamente las lecturas con que nos atoramos algunos días antes, o tal vez la labor paciente de investigación; pero está muy lejos de atacar el mal en sus raíces como quiso hacerlo la reforma $(1921 c: 66-67)$. 
En 1925, sus trabajos empiezan a ser firmados como «profesor de economía política», periodo en que ya había sido designado como subdirector de la Dirección General de Estadística de la Nación.

Como lo hace notar desde las primeras palabras del informe, sus críticas no menguaron mucho y menos los señalamientos para las transformaciones de la dirección, a pesar de que recientemente la había ocupado Alejandro E. Bunge, su exprofesor y apoyo en muchas épocas en el pasado («Anotaciones a la estadística nacional», Prebisch, 1925a). ${ }^{32}$ Gran parte del empeño del diagnóstico se finca en convencer a las autoridades de la importancia de conseguir máquinas estadísticas de compilación y tabulación de datos para reorganizar los distintos departamentos.

Durante la segunda parte del año de 1925, como subdirector de la Dirección de Estadística, intentó reformar la estructura de la oficina y preparó «Anotaciones demográficas. A propósito de la teoría de los movimientos de la

132/ «El siguiente memorándum fue presentado al Excmo. señor Ministro de Hacienda de la Nación. Ha tenido como fin poner de relieve las deficiencias más graves de nuestra estadística nacional, y sugerir los medios que a mi juicio resultarían más acertados para corregirlas. Si es bien difícil decir hasta donde aquella crítica y estas sugestiones son originales, es sencillísimo, sin embargo, descubrir el origen de la preocupación que me ha llevado a formularlas. Hace algunos años, el ingeniero A. E. Bunge, exdirector General de Estadística de la Nación, al notar en mí un cierto interés por estos asuntos - en el curso que entonces desarrollaba en la Facultad de Ciencias Económicas - comenzó a impartirme un estímulo tal, que mi interés se transformó en verdadero entusiasmo. Con el correr del tiempo, al entusiasmo sucede la preocupación, y hoy ella encuentra el terreno más propicio para dar sus frutos, si es que ha de darlos. Y durante, y después de este cambio, no cejó el ingeniero Bunge en su empeño en formarme estadístico: abrióme de par en par las puertas de su oficina para que yo analizara en ella todos sus procedimientos; puso especial empeño en explicarme las deficiencias que aún había de subsanar y los medios para lograrlo en el futuro; publicó mis primeros artículos en esta revista y consiguió que el ex ministro doctor me enviase al extranjero a estudiar ésta y otras cuestiones conexas. De este modo he tenido la suerte de poder estudiar la materia, no solamente en el aula universitaria, sino también en nuestra propia administración y en el extranjero. La exposición de las deficiencias que señalo y del plan de trabajo que formulo, responde pues a algo así como una segunda etapa de la obra realizada por el director Bunge y prevista por él, en su interés por el futuro de la estadística nacional a la cual consagró una década de eficiente labor como estadístico oficial» (1925a: 404). 
población» (1926a). Entre los primeros aspectos de la vida como subdirector fue convencer y derrotar todos los impedimentos para modernizar el proceso de tabulación de los datos con máquinas Hollerith. ${ }^{33}$ De sus escritos sobre las cuestiones demográficas, por otra parte, podemos destacar una de sus primeras expresiones sobre los métodos y las formas científicas, no obstante que previamente podemos encontrar señalamientos en torno a lo «experimental» $y$ «ciencia experimental» nunca antes definidas:

Las teorías experimentales, que al erigir los hechos en único y estricto juez de su valor, sólo son aceptadas como verdaderas si concuerdan satisfactoriamente con la realidad [...] aquellas teorías que alejándose en mayor o menor grado de la experiencia objetiva, obtienen su aprobación, no por explicar en forma adecuada los fenómenos concretos, sino por

133/ «Para convencer al director que había que traerlas nos hicieron alquilar. Las máquinas se alquilaban. Hubo una resistencia feroz del personal, comenzando con un señor Biocchi, funcionario muy dedicado, que era el que clasificaba las fichas. Pero él decía que tenía la clasificación en la cabeza, y yo le pedí dónde estaba el código para traducir el número a fin de que se perforara. Bueno, puse dos secretarias a su lado, una a cada lado, para que cuando él pusiese la fichita, de acuerdo con su memoria, en el casillero, anotasen. Entonces él, después, a los pocos días, trajo un papel muy gastado y sucio donde estaban los códigos. Así fue la cosa [...] RP. En realidad, la Dirección de Estadística se había concentrado en el comercio exterior. El director, (Alfredo) Lucadamo, era un hombre de carrera que me brindó en forma constante toda su amistad. Al principio se opuso, pero después se dio cuenta y se plegó con gran entusiasmo. Yo trataba de ampliar la órbita de la dirección. La estadística demográfica estaba en el Departamento Nacional de Higiene y era muy rudimentaria. Me voy acordando que una vez una doctora Sachelo escribió un comentario increíble diciendo: los datos de población demuestran que la proporción de gente que muere entre 65 y 70 años es menor que la que muere entre los 40 y 50 años. No se puede relacionar la tasa de mortalidad con la población de ese sector. Esto te da una idea de la pobreza que reinaba en las estadísticas de población. Yo fui a ver al doctor Araoz Alfaro, Director General de Higiene, proponiéndole que traslade todo eso a la Dirección de Estadística. Él se inclinaba favorablemente, pero por una resistencia burocrática ahí quedaron las cosas. Con todo, yo tenía la idea de que aún cuando no estuviera esa estadística bajo nuestra dirección, porque era necesaria una dirección técnica, que en la Dirección de Estadística hicieran una proyección global de las estadísticas de población. No se logró. No se logró» (Prebisch, 2006). 
estar de acuerdo con nuestros prejuicios, sentimientos, pasiones o intereses (Prebisch, 1926a: 421).

La búsqueda de «causas» en las ciencias sociales conducen a una «verdadera logomaquia» (ibid: 456) debido a la interdependencia de los fenómenos. Ello exige mucho cuidado sobre la designación de «causas»y «efectos», que a su vez pueden convertirse en «causas» y caer en un «círculo vicioso» (ibid: 456).

Pero de todas maneras, tanto en la demografía como en las ciencias sociales, dice Prebisch, las teorías experimentales tienden a prevalecer sobre las concepciones anteriores, tradición donde ubica a Malthus. Las conferencias y las respectivas publicaciones intentan relacionar ciclos migratorios con el ascenso y el descenso del comercio exterior, ciclos de nupcialidad y respectivamente los económicos, comparaciones entre distintos países y la Argentina: tasas de natalidad, mortalidad y crecimiento vegetativo, así como la relación entre la natalidad y la nupcialidad.

No obstante, la ausencia de una periodicidad constante en los censos y sus formas:

dentro de estas tendencia seculares, a través de un largo periodo, nótase una serie de oscilaciones o variaciones [...] Cada oscilación presenta su propio ciclo, esto es, su movimiento de ascenso y de descenso y se desarrolla en un periodo relativamente corto de años si se lo compara con el de la tendencia secular. Por medio de procedimientos estadísticos que no es del caso explicar, las variaciones en cortos periodos se prestan a ser analizadas independientemente, considerándolas simples desviaciones de la tendencia secular. A su vez, esta última puede ser estudiada eliminando esas perturbaciones que acecen en cortos lapsos (1926a: 426-427-428).

Es cierto que Prebisch no explica los procedimientos para establecer el fenómeno cíclico, pero en un apéndice nos remite a los mismos para calcular 
la «tendencia secular y las variaciones a corto término», citando al Harvard University Commitee on Economic Research y con nota a pie de página indica al «Review Economic Statistics (sic), 1919, Explanation of the data and method used in the index of General Business Conditions» (Prebisch, 1926a: 464).

Como los ciclos económicos y demográficos que se manifiestan en el periodo 1869-1925 estudiado en este trabajo, no duran más de once años, hemos juzgado que la tendencia secular (secular trend) estaría bien representada por un promedio encadenado de la misma duración, o sea once años. Para calcular el promedio encadenado de cada año, hemos sumado a la cifra real de ese año las cifras reales de los cinco años anteriores y de los cinco años posteriores. En esta forma se ha querido anular los movimientos ascendentes y descendentes de los ciclos, compensando unos con otros. Las variaciones a corto término reflejan, por lo contrario, los movimientos de los ciclos, aislándolos de la marcha a largo término, de la tendencia secular de los fenómenos. Tales variaciones son, pues, las desviaciones de las cifras reales con respecto a la tendencia secular; y para calcularlas basta extraer las diferencias positivas o negativas entre ambas y transformarlas en simples porcentajes de dicha tendencia secular. Como al presentar gráficamente las variaciones a corto término se presentarían aristas muy bruscas que habrían hecho confuso el diagrama, hemos debido suavizarlas. Para ellos calculamos promedios encadenados de tres años de las cifras de la tendencia secular y de las cifras reales y averiguamos las desviaciones de las últimas con respecto a las primeras, en la forma expresada (Prebisch, 1926a: 464).

En el mismo sentido, unos meses más adelante, criticando y discutiendo las conferencias de Luis Olariaga — «De cómo discurre el profesor Olariaga» (Prebisch, 1927a)—, recomendaba a «Mr. Snyder, estadísticos del Federal Reserve Board», Business Cycles and their Measurements (ibid.: 473). De hecho, al cuestionar el método de Olariaga, de acceder a la realidad por medio de 
interrogar a la gente, propone investigar la realidad, como lo hacen los economistas de Harvard y Cambridge, «valiéndose de múltiples series estadísticas para averiguar la naturaleza de los periodos del ciclo económico». Solamente así, retomando un dicho de Olariaga, dice Prebisch, se puede pisar la «tierra santa» (ibid.: 466) que pregona. También nos alecciona con el «instrumental científico» para obtener la tendencia secular, eliminando los periodos ascendentes con los descendentes por el «cálculo de los promedios móviles» (Prebisch, 1927a: 473). Con ellos se destacan los ritmos de crecimiento para evaluar la tesis de Olariaga sobre el estancamiento argentino.

En esta forma se podrá comparar, a través de varias décadas, el ritmo de crecimiento característico del comercio exterior. Pero es obvio que al necesitarse para el cálculo del promedio móvil, debido a la naturaleza de nuestro ciclo, por lo menos cinco años anteriores y cinco posteriores al año cuya tendencia secular se quiere determinar, el procedimiento no permitiría averiguar la tendencia de los cinco últimos años. Ya se ha señalado uno de los métodos satisfactorios para esto último (Prebisch, 1927a: 473).

Igualmente, Prebisch da cátedra a Olariaga para facilitar la comprensión y las comparaciones:

Hemos recurrido a ellos [gráficos logarítmicos] por cuanto tienen la ventaja de que la misma distancia vertical representa, en cualquier parte del gráfico, idéntica intensidad de crecimiento. En cambio, en el gráfico en escala natural, la distancia vertical señala siempre igual incremento absoluto, aunque el crecimiento relativo que resulta sea diferente según el punto de la curva a que se refiera [a nota de pie de página agrega] Por ejemplo, en 1871 nuestro intercambio comercial fue de 73 millones de pesos oro, y en 1873 de 121 millones: el crecimiento absoluto fue de 48 millones y el relativo de 65.7\%; el intercambio fue de 199 millones y de 302 millones en 1899: el crecimiento absoluto fue de 103 millones y el 
relativo de $51.7 \%$. El gráfico en escala natural presenta los incrementos absolutos; el gráfico logarítmico los incrementos relativos: de ahí su ventaja en el presente caso (Prebisch, 1927a: 469)..$^{34}$

Con los cambios gubernamentales, así como en la Sociedad Rural Argentina, Luis Duhau asume la presidencia de la institución ganadera. Persona con quien Prebisch estará relacionado en los próximos años en varias tareas de asesoría gubernamentales y personales. Viaja con él como asesor, en 1927, a Estados Unidos y Canadá, para examinar el régimen del comercio exterior y los graneros canadienses y aprovecha para proponerle la creación de un informe anual estadístico, lo cual se materializa en «Régimen de pool en el comercio de carnes: informe técnico» (1927b).

Prebisch obviamente se sentía a gusto porque «Régimen de pool...» (Prebisch, 1927b), publicado por la Sociedad Rural, presenta todos sus argumentos elaborados previamente en sus confrontaciones con la oligarquía ganadera sobre la situación ganadera, ${ }^{35}$ a lo cual en esta ocasión le añade la idea de que el «pool» podría interrumpir «un proceso de selección económica al mantener con vida empresas menos eficientes; y la subsistencia de éstas no representaría ventaja alguna para los productores de ganado. Más bien, podría traducirse en su perjuicio, en ciertos casos» (Prebisch, 1927b: 497).

Asimismo, el Anuario de la Sociedad Rural Argentina (Prebisch, 1928a) marca un hito en la historia de la información estadística de la economía argentina. El Anuario... lleva un prólogo del presidente de la Sociedad Rural Argentina, Luis Duhau, y abajo dice «Compilado bajo la dirección de Raúl Prebisch». ${ }^{36}$ Posteriormente, cuando Duhau termina su gestión en la Socie-

\footnotetext{
134/ Una, entre las varias ocasiones en que repetirá este párrafo en los años que siguen, véase, por ejemplo, Prebisch (1928a: 502-503).

135/ Prebisch, 1922a y $1922 \mathrm{f}$.

${ }^{136 /}$ Prebisch presenta el Anuario al presidente de la Comisión de Estadística de la Sociedad Rural Argentina, firmado Raúl Prebisch (asesor técnico de la Sociedad Rural Argentina).
} 
dad Rural, y queda nombrado presidente del Banco de la Nación, Prebisch deja de asesor a la Sociedad Rural y abandona la Subdirección de Estadística ante el ofrecimiento de crear la Oficina de Investigaciones Económicas, en el Banco de la Nación.

De manera análoga, como se constituyó el cargo de la Subdirección de Estadística con proyecto anticipado elaborado por su futuro ocupante, nos encontramos a Prebisch escribiendo la «propuesta» para la creación de la Oficina de Investigaciones en el Banco de la Nación: «Organización de la Oficina de Investigaciones Económicas» (Prebisch, 1928c), sugerida por el presidente de la Sociedad Rural Argentina, Luis Duhau, quien quedó como director del Banco de la Nación.

Se presenta el memorándum escrito por la pluma de Prebisch y firmado por el presidente don Tomás E. Estrada y el señor director L. Duhau. Entre las reformas, cabía cambiar el nombre de Oficina de Economía, Fomento y Estadística a Oficina de Investigaciones Económicas o de Economía y Estadística, suprimiéndose el término «Fomento», que nada tiene que ver con las tareas objetivas de investigación estadística. La decisión de si debe o no fomentar corresponde a la política bancaria, determinada por el directorio (Prebisch, 1928c: 499). Igualmente se indica:

Una falta de una publicación seria, con datos de fuente insospechable y prolijamente elaborados, que nos presente las variaciones de la situación económica argentina en sus distintos aspectos y nos informe sobre las alteraciones más significativas de las economías extranjeras [...] El Banco de la Nación Argentina, que como ninguna institución del país, abarca todo el panorama de nuestra economía, se encuentra en condiciones excepcionales para llenar aquella necesidad mediante una Revista o Boletín Mensual [...] algunas instituciones muy serias del extranjero comenzaron a publicar sus barómetros económicos. Consisten éstos en un análisis de los elementos primordiales de al situación económica presente, con el fin de prever las variaciones futuras. La elaboración de 
barómetros requiere la investigación minuciosa de series estadísticas que abarquen por lo menos dos ciclos económicos, puesto que la previsión de los barómetros se basa en la experiencia de tales ciclos [...] requiere [...] algunas estadísticas bancarias y económicas que no existen en nuestro país (ibid., 1928c: 500).

El memorándum resalta:

Aparte de la selección del director de la Oficina, la del personal técnico que haya de secundarlo en sus funciones debe exigir el mayor cuidado. Se trata de una oficial de investigaciones científicas [...] Los estudios económicos recién comienzan a efectuarse metódicamente en la Argentina, razón por la cual el banco tendrá que formar buen parte del personal técnico requerido (Ibid., 1928c: 501).

Efectivamente, Prebisch quedó en 1928 como director de la Oficina... ${ }^{37}$ y con la plena libertad para contratar a los técnicos de su confianza, grupo que lo seguirá en sus próximas obligaciones. Su responsabilidad en la publicación Revista Económica, ${ }^{38}$ hasta $1934,{ }^{39}$ es innegable. Desde sus inicios, presentó sistemáticamente la evolución económica del país. El golpe de Estado, del 6 de septiembre, por parte de José Félix Uriburu, cambiaría su vida radicalmente en los próximos años, llegando a formar parte de los asesores más importantes y funcionarios

137/ En «Propósito de esta publicación», se declara: «Las tareas de organización de la Oficina han sido puestas bajo la experta dirección técnica del señor Raúl Prebisch, profesor de Economía Política en la Universidad de Buenos Aires [...] la revista procurará presentar los datos más significativos de la vida económica nacional [...] Queda, pues, iniciada una obra que tardaba en realizarse en nuestro país» (Prebisch, 1928d: 529-530).

138/ Prebisch, 1928c; 1928d; 1929a; 1929b; 1929c; 1929d; 1930a; 1930b; 1930c; 1932b; 1932c; 1932d; 1933a, 1933c; 1933d; 1934d; 1934k;1934l; todas en la revista en cuestión.

139/ Año en que cesa de publicarse por su compromisos para organizar y construir el Banco Central (Fernández López, 1991: 434). 
gubernamentales en una década política denominada «infame». Una mañana, volviendo de sus tradicionales paseos por la zona de Palermo a fines de septiembre, Ernesto Malaccorto, con quien compartía hospedaje, le dice que el ministro de Hacienda, Enrique S. Pérez, lo andaba buscando. Prebisch, que siempre le seguía sus bromas, con mucha seriedad le responde: «seguramente quiere que sea el próximo subsecretario de Hacienda, lo pensaré detenidamente».

En síntesis, el artículo intentó describir las actividades y la evolución intelectual del joven Prebisch (Pérez Caldentey y Vernengo, 2012; Dosman 2008), proveniente de la provincia de Tucumán, en las postrimerías de la Argentina de la Bella Época, hasta unos días antes de su nombramiento como subsecretario de Hacienda a los 29 años. Prebisch personifica el ascenso y el apogeo de la modernización estatal y de sus saberes (Caravaca, 2012 y 2011). Y el espacio dedicado al tono, a la actitud y al vocabulario del personaje no quiso confundir al lector con un experimento sobre si se trataba de «petulancias de un principiante ${ }^{40}$ o del surgimiento de una singular luminaria del pensamiento latinoamericano.

\section{ReFERENCIAS}

Barone, Enrico (1931), Principios de economía politica, Buenos Aires, Universidad de Buenos Aires.

Borges, Jorge Luis (1964), «El otro, el mismo», Obras Completas II, Buenos Aires, Emecé Editores.

Braun Rodríguez, Carlos (2000), «Orígenes del socialismo liberal. El caso de Juan B. Justo», Cuadernos de CC. EE. $y$ EE, núm. 38.

Caravaca, Jimena (2012), El liberalismo económico «a la Argentina». Articulación entre saberes y prácticas alrededor de cuatro crisis, 1873-1935. Tesis doctoral, Facultad de Ciencias Sociales, y Université Paris 7 Diderot.

140/ Expresión de Prebisch (Prebisch, 1921h: 160). 
(2011), ¿Liberalismo o intervencionismo? Debates sobre el rol del Estado en la economía argentina. 1870-1935, Buenos Aires, Editorial Sudamericana. Cortés Conde, Roberto (2001), «Raúl Prebisch: Los años de gobierno», Revista de la Cepal, núm. 75.

Dosman, Edgar (2008), The Life and Times of Raúl Prebisch (1901-1986), McGill-Queen's University Press.

Fernández López, M. (1991) en Prebisch, (1991a), y a cargo de la edición de (Prebisch, 1991a; 1991b; 1991c; 1993).

(1996), «El ciclo económico argentino: estudios de Raúl Prebisch», Ciclos, año vi, vol. VI, núm. 10, primer semestre.

(2000a), «Una moneda estableः Irving Fisher y Alejandro Bunge», El Economista, 7/4: 10 .

(2000b), «Ugo Broggi, a neglected precursor in modern mathematical economics», Anales de la Asociación Argentina de Economía Política. (2001), «El pensamiento económico (1914-1982)», Nueva Historia de la Nación Argentina, viı, Buenos Aires, Academia Nacional de la Historia.

(2002), «Recepción del pensamiento de Pareto en Argentina», Anales de la Asociación Argentina de Economía Política, Buenos Aires. (2008), «La ciencia económica argentina entre guerras (1918-1939)», Universidad de Buenos Aires.

(2008a), «Raúl Prebisch y su alma máter», II Congreso Internacional de Economía y Gestión. Econ 2008.

Fisher, Irving (1911), The Purchasing Power of Money: Its Determination and Relation to Credit Interest and Crises, The Macmillan Company, New York. García Costa, Victor (1997), Alfredo Palacios. Entre el claves y la Espada, Editorial Planeta Argentina, Buenos Aires Argentina.

Imaz, Jose Luis de (1974), «Alejandro E. Bunge, Economista y Sociólogo», Desarrollo Económico, vol. 14, núm. 55, octubre-diciembre.

Jèze, Gaston (1923), Las Finanzas Públicas de la República Argentina, Buenos Aires. 
Loвоs, E. (1925), «Prólogo» en Miguel Angel Carcano, Evolución histórica del régimen de la tierra pública, 1810-1916, Buenos Aires.

Magariños, M. (1991), Diálogos con Raúl Prebisch, Fondo de Cultura Económica, México.

Mallorquin, C. (2006), «Raúl Prebisch Before The Ice Age» en Edgar Dosman The Life and Times of Raúl Prebisch (1901-1986), McGillQueen's University Press. (2007), «The unfamiliar Raúl Prebisch» en Pérez Caldentey y Vernengo, (2012), «Retrato de un joven economista: la evolución de las opiniones de Raúl Prebisch sobre el ciclo económico y el dinero, 1919-1949», Revista CEPAL, núm. 106, abril.

(2000), «Un texto de Raúl Prebisch», Aportes, revista de la Facultad de Economía, BUAP, año v, núm. 14, pp. 11-14. (2003), Conversaciones con Don Victor Urquidi, entrevista inédita.

Menger, Anton (1899), The Right to the Whole Produce of Labour, Augustus M. Kelley, New York, 1970.

Molteni, G. R. (2003), «Structural change in Argentina: Economic Ideas, Economic Policy and Institutional Constraints During the Inter-War Period. The Case of Alejandro E. Bunge», Cuestiones Sociales y Económicas, septiembre, año 1 , núm. 2.

Morgan, Mary. S. (1990), The History of Econometric Ideas, Cambridge University Press.

Moore Ludwell, H. (1914), Economic Cycles: Their Law and Cause, Augustus M. Kelley, New York, 1967.

Prebisch, Raúl (1991a), Raúl Prebisch. Obras 1919-1948, vol. I, Fundación Raúl Prebisch, Buenos Aires. (1991b), Raúl Prebisch. Obras 1919-1948, vol. II, Fundación Raúl Prebisch, Buenos Aires.

(1919a), «Investigaciones sobre el "Estándar” de vida en China» en Prebisch (1991a). (1919b), «El costo de la vida en Italia» en Prebisch (1991a). 
(1919c), «La guerra y la población en Francia» en Prebisch (1991a). (1919d), «Departamento de Investigaciones sobre fatiga industrial» en Prebisch (1991a).

(1919e), «La riqueza y renta del mundo antes de la guerra» en Prebisch (1991a).

(1919f), «Geografía económica» en Prebisch (1991a).

(1919g), «La situación financiera de Francia» en Prebisch (1991a). (1920a), «:Salarios a oro?», La Hora en Prebisch (2006). (1920b), «Cuestión social», en Prebisch (1991a). (1920c), «El medio circulante y los precios en Italia» en Prebisch (1991a). (1920d), «El medio circulante y los precios» en Prebisch (1991a). (1920e), «Comentarios sobre el trabajo Estadística de Precios y números indicadores del Perú por Oscar F. Arrus» en Prebisch (1991a). (1920f), «Deuda pública de las naciones antes y después de la guerra» en Prebisch (1991a).

(1920g), «Comentarios sobre el libro de Irving Fisher, Stabilizing the Dollar, Nueva York, 1920», en Prebisch (1991a).

(1920h), «Principios de desinflación» en Prebisch (1991a).

(1920i), «Ajuste de los salarios al costo de la vida», en Prebisch (1991a). (1920j), «La Organización de las estadísticas», en Prebisch (1991a). (1921a), «Planes para estabilizar el poder adquisitivo de la moneda», en Prebisch (1991a).

(1921b), «La Conferencia de Bruselas», en Prebisch (1991a). (1921c), «Anotaciones sobre la reforma», en Prebisch (1991a). (1921d), «La conferencia financiera internacional de 1920», en Prebisch (1991a).

(1921e), «Comentarios sobre el trabajo de Juan B. Justo, Estudios sobre la moneda, tercera edición, Buenos Aires», en Prebisch (1991a). (1921f), «El trabajo libre», en Prebisch (1991a).

(1921g), «La ortopedia bancaria del profesor Piñero», en Prebisch (1991a). 
Prebisch, Raúl (1921h), «Anotaciones sobre nuestro medio circulante. A propósito del último libro del Dr. Norberto Piñero» (cuatro partes: I en 1921 y II-III-IV en 1922), en Prebisch (1991a). (1922a), Información estadística sobre el comercio de carnes. Primera parte: el mercado británico, Sociedad Rural Argentina, Oficina de Estadística, Buenos Aires, 1922, pp. 3-74; aparece con el título «Información estadística sobre el comercio de carne vacuna», en Prebisch (1991a). (1922b), «Carácter y finalidad de los cursos de seminario», en Prebisch (1991a).

(1922c), «Sobre la degradación del marco y el pago de las reparaciones», en Prebisch (1991a).

(1922d), «Anotaciones sobre la crisis ganadera», en Prebisch (1991a). (1923a), «La Caja Internacional de Conversión. El proyecto monetario del Dr. Frers», en Prebisch (1991a).

(1923b), «A propósito de la primera conferencia del profesor Jèze», en Prebisch (1991a).

(1923c), «La sociología de Vilfredo Pareto», en Prebisch (1991a).

(1924a), «El problema de la tierra», en Prebisch (1991a).

(1924b), «Establecimiento de nuestra administración financiera sobre bases comerciales», en Prebisch (1991a).

(1924c), «Determinación de la capacidad imponible. Método australiano de promedios», en Prebisch (1991a).

(1924e), «Primer informe del Dr. Raúl Prebisch sobre sus estudios financieros y estadísticos en Australia, 14 de agosto de 1924», en Prebisch (1991a).

, (1925a), «Anotaciones a la estadística nacional», en Prebisch (1991a). , (1926a), «Anotaciones demográficas. A propósito de la teoría de los movimientos de la población»,(cuatro partes, I-II-III-IV), en Prebisch (1991a).

(1927a), «De cómo discurre el profesor Olariaga», en Prebisch (1991a). (1927b), «Régimen de pool en el comercio de carnes: informe técnico», 
en El Pool de frigoríficos: Necesidad de la intervención del Estado, Sociedad Rural Argentina, Buenos Aires, 1927, en Prebisch (1991a). (1928a), Anuario de la Sociedad Rural Argentina: Estadísticas económicas y agrarias, 1928, Anuario de la Sociedad Rural Argentina, núm. 1, Establecimiento Gráfico Luis L. Gotelli, Buenos Aires, 1928, «Ritmo de crecimiento de la economía Nacional», en Prebisch (1991a).

(1928b), «Organización de la Oficina de investigaciones económicas», «Ritmo de crecimiento de la economía Nacional», en Prebisch (1991a). (1928c), «Propósitos de esta publicación», en Prebisch (1991a).

(1929a), «La posición de 1928 y las variaciones económicas de la última década», en Prebisch (1991a).

(1929b), «El movimiento Internacional del oro», en Prebisch (1991a). (1929c), «La carne Argentina en el mercado británico» en Prebisch (1991a).

(1929d), «Los pagos internacionales y el ciclo monetario», en Prebisch (1991a).

(1930a), «El Estado económico», en Prebisch (1991a).

(1930b), «El Estado Económico», en Prebisch (1991a).

(1930c), «El Estado Económico», en Prebisch (1991a).

(1932a), «Impuesto a los réditos», en Prebisch (1991b).

(2006 [1983]), «Conversaciones con Raúl Prebisch» (entrevista de Julio González del Solar realizada el 9 de julio 1983; mimeografiado, inédito); «Introducción a la moneda y los ciclos económicos» $y$ «¿Salarios a oro?» pueden verse en 〈www.moebio.uchile.cl, Textos para el Estudio del Pensamiento de Raúl Prebisch.

Pantaleoni, Maffeo (1898), Manuale Di Economia Pura, versión en inglés por Kelly \& Millan Inc. Neva York, 1957.

Pérez Caldentey, E. y M. Vernengo (2012), «Retrato de un joven economista: la evolución de las opiniones de Raúl Prebisch sobre el ciclo económico y el dinero, 1919-1949», Revista CEPAL, núm. 106, abril.

Pollock D., D. Kerner y J. Love (2001), «Entrevista inédita a Prebisch: lo- 
gros y deficiencias de la Cepal», Revista de la Cepal, núm, 75. Santiago de Chile, diciembre.

Roque Gondra, L. (1933), Elementos de Economía Política, Buenos Aires, la Facultad.

(1943), Ensayo sobre una teoría general de las fluctuaciones económicas elementos de dinámica económica, Imprenta de la Universidad de Buenos Aires.

(1937),Teorías antiguas y recientes sobre la moneda, el crédito y los ciclos económicos, Buenos Aires, Tomás Palumbo.

(1932), «La circulación monetaria en la República Argentina», La Vanguardia, Buenos Aires.

(1934), Problemas sociales y económicos del momento, Buenos Aires, La Facultad.

(1937), El radicalismo y la política del momento motivos de crítica y polémica, Buenos Aires, La Facultad.

Sember, Florencia (2010), The Origins and Evolution of the, Monetary Thought of Raúl Prebisch, tesis doctoral, Università di Macerata and from the Université de Paris 1, Panthéon Sorbonne.

Sunkel, Osvaldo (2011), «Reflexiones sobre la vida y obra de Raúl Prebisch» en A. Bárcena, E. J. Dosman y O. Sunkel, Homenaje a Raúl Prebisch (1901-1986), Naciones Unidas, Santiago de Chile.

Weintraub, Roy E. (2002), How Economics became a Mathematical Science, Duke University Press.

Williams, J. H. (1920), Argentine International Trade Under Inconvertible Paper Money, 1880-1900, Cambridge, Harvard University Press.

Yule, G. U. (1911), An Introduction to the Theory of Statistics, Chales Griffin $\&$ Co., Londres. 